\title{
Spectroscopic and electrokinetic evidence for a bifunctional mecha- nism of the oxygen evolution reaction
}

\author{
Lichen Baił, Seunghwa Leeł, Xile Hu* \\ Laboratory of Inorganic Synthesis and Catalysis, Institute of Chemical Sciences and Engineering, École Polytech- \\ nique Fédérale de Lausanne (EPFL), ISIC-LSCI, 1015 Lausanne, Switzerland
}

\begin{abstract}
The oxygen evolution reaction (OER) is an essential anodic reaction in many energy storage processes. OER is most often proposed to occur via a mechanism involving four consecutive proton-coupled electron transfer (PCET) steps, which imposes a performance limit due to the scaling relationship of various oxygen intermediates. A bifunctional OER mechanism, in which the energetically demanding step of the attack of hydroxide on a metal oxo unit is facilitated by a hydrogen atom transfer to a second site, has the potential to circumvent the scaling relationship. However, the bifunctional mechanism has hitherto only been supported by theoretical computations. Here we describe an operando Raman spectroscopic and electrokinetic study of two highly active OER catalysts, $\mathrm{FeOOH}-\mathrm{NiOOH}$ and NiFe layered double hydroxide (LDH). The data support two distinct mechanisms for the two catalysts: $\mathrm{FeOOH}-\mathrm{NiOOH}$ operates by a bifunctional mechanism where the rate-determining $\mathrm{O}-\mathrm{O}$ bond forming step is the $\mathrm{OH}^{-}$attack on a $\mathrm{Fe}=\mathrm{O}$ coupled with a hydrogen atom transfer to a Ni $\mathrm{Ni}_{-} \mathrm{O}$ site, whereas NiFe LDH operates by a conventional mechanism of four consecutive PCET steps. The experimental validation of the bifunctional mechanism enhances the understanding of OER catalysts.
\end{abstract}

\section{Introduction}

The oxygen evolution reaction (OER) is an essential anodic reaction for many cathodic electrochemical reactions, such as hydrogen evolution reaction (HER), $\mathrm{CO}_{2}$ reduction reaction (CRR), and $\mathrm{N}_{2}$ reduction reaction (NRR), which may be used to generate renewable fuels and valuable chemicals. $\frac{1-2}{}$ An electrocatalyst, typically a metal oxide or oxyhydroxide, is required for OER to occur at a conceivable rate. ${ }^{3-5}$ The OER involves four electrons and protons, rending it mechanistically complex.3, 5-7 For OER catalyzed by metal oxides and oxyhydroxides, the most commonly assumed mechanism involves four consecutive proton-coupled electron transfer, where the $\mathrm{O}-\mathrm{O}$ bond forming step is nucleophile attack of water or hydroxide on a metal oxo species (Figure 1a). $\underline{6}, \underline{8}$ DFT computations revealed a scaling relationship between the adsorption energies of $\mathrm{OH}^{*}, \mathrm{O}^{*}$, and $\mathrm{OOH}^{*} . \underline{8-9}$ In particular, the difference of the adsorption energies of ${ }^{*} \mathrm{OH}$ and ${ }^{*} \mathrm{OOH}$ is always $3.2 \mathrm{eV}$ for nearly all metal oxides. This scaling relationship poses an upper limit on the performance of OER catalysts, which has a theoretical overpotential of about $0.4 \mathrm{eV} . \underline{8-9}$

To break the performance limit imposed by the scaling relationship, a change of catalytic mechanism is required. An alternative mechanism involves the combination of two metal oxo species as the O-O bond forming step (Figure $1 b)$. Although there is theoretical debate in whether this $\mathrm{O}$ $\mathrm{O}$ bond forming step is kinetically favourable compared to the nucleophilic attack step,,$^{12-13}$ electrokinetic studies seem to support such a mechanism in a number of systems. ${ }^{14-16}$ In addition to these two conventional mechanisms, a thirdtype, so-called "bifunctional" mechanism has recently been proposed. $\stackrel{11,17-19}{19}$ This mechanism involves two catalytic sites, often based on two different metal ions, which work in a cooperative manner (Figure 1c). One site provides the electrophilic $\mathrm{M}=\mathrm{O}$ entity, while the other side provides a hydrogen atom acceptor (A). Although the direct nucleophilic attack of an $\mathrm{OH}^{-}$on the $\mathrm{M}=\mathrm{O}$ to form the $\mathrm{M}-\mathrm{OOH}$ intermediate is energetically too unfavourable, a concerted hydrogen atom transfer to the neighbouring acceptor significantly lowers the energetics.

Until now, the bifunctional mechanism is supported by DFT computations only..$^{11,17-19}$ In a previous study, we developed an unconventional iron nickel catalyst, FeOOH$\mathrm{NiOOH}$, that was significantly more active than Ni-Fe oxyhydroxides and related layered double hydroxides $\left(\mathrm{NiFeO}_{\mathrm{x}} \mathrm{H}_{\mathrm{y}}\right.$ and $\left.\mathrm{NiFe} \mathrm{LDH}\right)$, which were the benchmark OER catalyst in alkaline medium. ${ }^{19}$ Operando X-ray absorption spectroscopy revealed the catalyst as nanoclusters of $\gamma$-FeOOH covalently linked to a $\gamma$-NiOOH support. According to DFT computations, this structure could enable a bifunctional mechanism where the $\mathrm{O}-\mathrm{O}$ bond forming step is a nucleophilic attack of $\mathrm{OH}^{-}$on a $\mathrm{Fe}=\mathrm{O}$ moiety coupled with a concerted hydrogen atom transfer to a nearby terrace $\mathrm{O}$ site on the $\gamma-\mathrm{NiOOH}$ support. Here we present in-situ Raman spectroscopy and electrokinetic data that support this mechanism. The experimental validation of the bifunctional mechanism stimulates both the mechanistic understanding and the design principles of OER catalysts. 
(a)

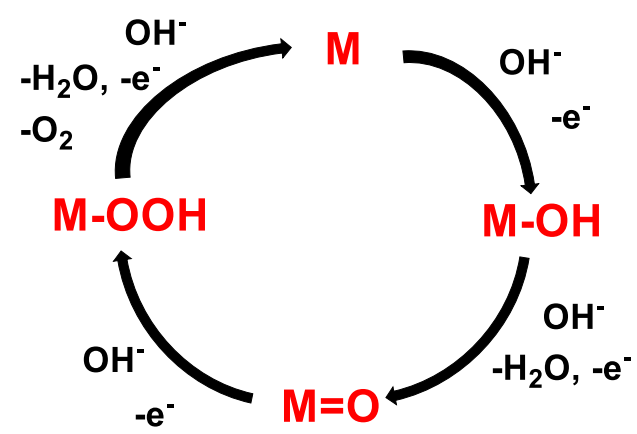

(b)

(c)
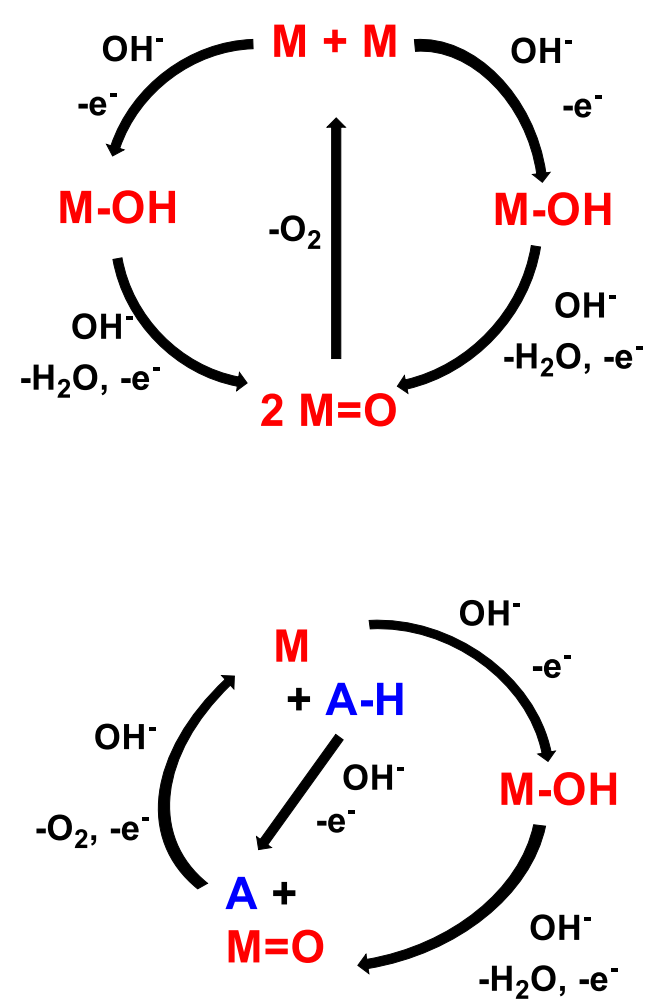

Figure 1. Three OER mechanisms. (a) A conventional mechanism involving four consecutive proton-coupled electron transfers; (b) A conventional mechanism involving combination of two metal oxo species as the $\mathrm{O}-\mathrm{O}$ bond forming step; (c) An unconventional 'bifunctional' mechanism. M represents an active metal center, A represents a hydrogen atom acceptor.

\section{Results}

\subsection{Compositions and activity of catalysts}

As described previously, $\mathrm{FeOOH}-\mathrm{NiOOH}$ was prepared by dipping a clean nickel form (NF) in a solution of $\mathrm{FeCl}_{3}$, drying in air at $80{ }^{\circ} \mathrm{C}$, followed by anodic activation in a Fecontaining $\mathrm{KOH} .19$ While previously we assigned the support as pure $\mathrm{NiOOH}$, we found in the present study that some Fe ions were incorporated in the lattice of $\mathrm{NiOOH}$, which resulted in a positive shift of the $\mathrm{Ni}(\mathrm{OH})_{2} / \mathrm{NiOOH}$ oxidation potential $\stackrel{20-22}{2}$ during the formation of $\mathrm{FeOOH}-$ $\mathrm{NiOOH}$ (Figure $\mathrm{S}$ ). The distribution of Fe was not uniform, according to transmission electron microscopy (TEM), and energy dispersed X-ray (EDX) mapping (Figure $\mathrm{S}_{2}$ and $\mathrm{S}_{3}$ ). Because Fe-doped $\mathrm{NiOOH}$ is an active OER catalyst,, $20-22$ to probe the possible influences of the Fe doping in the $\mathrm{NiOOH}$ support in the activity and mechanism, we chose NiFe LDH as a reference sample. Previous studies suggested the structure of NiFe LDH is the active motif of Fe-doped NiOOH. ${ }^{20}, 23$ Additionally, DFT computations suggested OER occurred via four consecutive PCET steps on this conventional NiFe oxyhydroxide catalyst. ${ }^{23-25}$ The NiFe LDH was prepared according to literature. $\underline{26}$ The compound was characterized by powdered X-ray diffraction (PXRD), transmission electron microscopy (TEM), and energy dispersed X-ray (EDX) mapping (Figure $\mathrm{S}_{4}$ and $\mathrm{S}_{5}$ ). The $\mathrm{Ni}$ and $\mathrm{Fe}$ ions appeared to be uniformly distributed in NiFe LDH,(Figure $\mathrm{S}_{5}$ ), and the Fe content was about $22 \%$.
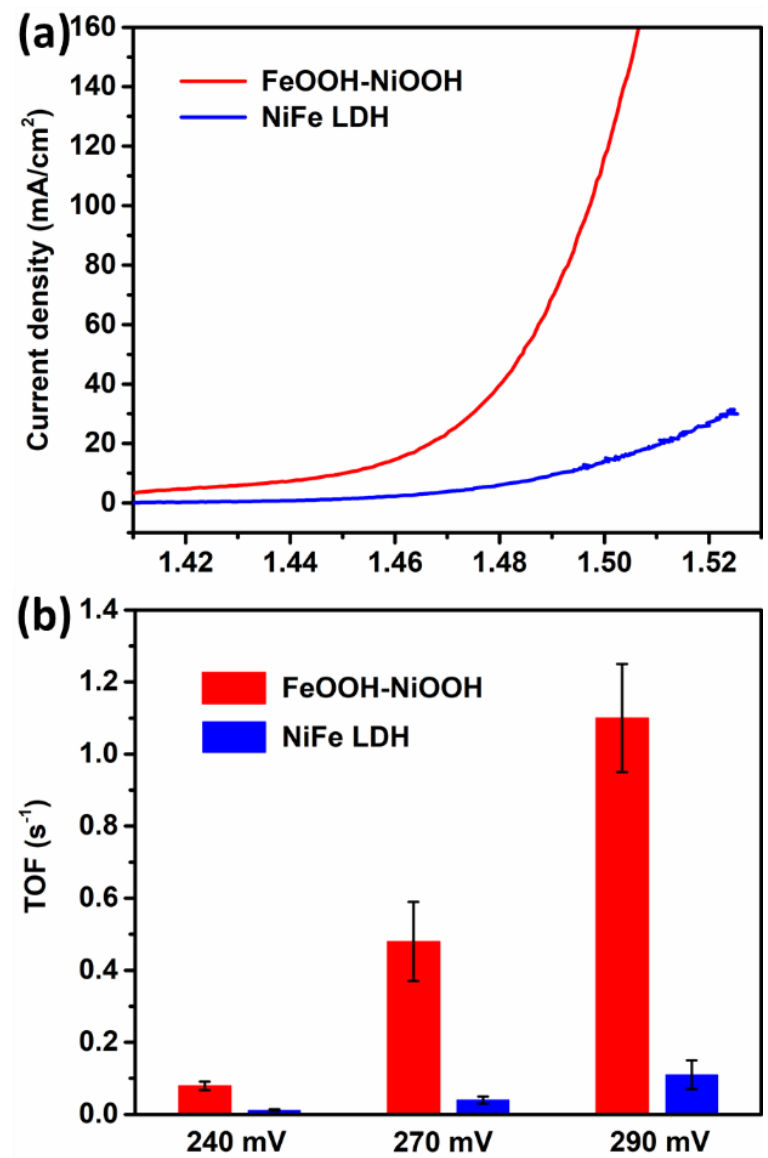

Figure 2. Electrocatalytic activity. (a) LSV curves of FeOOH$\mathrm{NiOOH}$ (red) and NiFe LDH (blue) in $1 \mathrm{M} \mathrm{KOH.} \mathrm{(b)} \mathrm{Compar-}$ ison of TOFs of FeOOH-NiOOH (red) and NiFe LDH (blue) at various overpotentials.

We compared the activity of $\mathrm{FeOOH}-\mathrm{NiOOH}$ and $\mathrm{NiFe}$ LDH with similar Fe loadings (Figure S6). To avoid the formation of some FeOOH-NiOOH on NF during OER test, ${ }^{19}$ the activity of NiFe LDH was tested on a carbon-cloth (CC) electrode. Both catalysts were activated by multiple cyclic 
voltammetric (CV) scans (Figure Sia, S7). The activation of $\mathrm{FeOOH}-\mathrm{NiOOH}$ was related to the incorporation of $\mathrm{Fe}$ ions and formation of $\mathrm{FeOOH}$ as reported previously. ${ }^{10}$ The activation of NiFe $\mathrm{LDH}$ was related to a morphology change that increased the surface area, which was indicated by the increase of areas of the oxidation of $\mathrm{Ni}(\mathrm{OH})_{2}$ to $\mathrm{NiOOH}$ (Figure $\mathrm{S}_{7}$ ). Moreover, TEM and HAADF-STEM images (Figure S2b, S8 and S9) showed that the initial, large lamellar structure cracked into small layers upon activation, while the $\mathrm{Fe} /(\mathrm{Ni}+\mathrm{Fe})$ ratio remained unchanged (Figure S5e and S9e). According to linear sweep voltammetry (LSV) data (Figure 2a and Sio), the $\mathrm{FeOOH}-\mathrm{NiOOH}$ is significantly more active than NiFe $\mathrm{LDH}$, both in apparent geometric activity (Figure 2a) and in electrochemical surface area (ECSA)-averaged activity (Figure S1o). The turnover frequencies (TOFs) were also compared assuming a bimetallic Ni-Fe active site for both catalysts (Figure $2 \mathrm{~b}$ ). The $\mathrm{FeOOH}-\mathrm{NiOOH}$ has TOFs that are about 10 times higher than those of NiFe LDH. These data indicate a difference in the active sites of $\mathrm{FeOOH}-\mathrm{NiOOH}$ and $\mathrm{NiFe}$ $\mathrm{LDH}$, and confirm that the Fe-doped NiOOH support had no noticeable contribution to the measured activity of $\mathrm{FeOOH}-\mathrm{NiOOH}$.
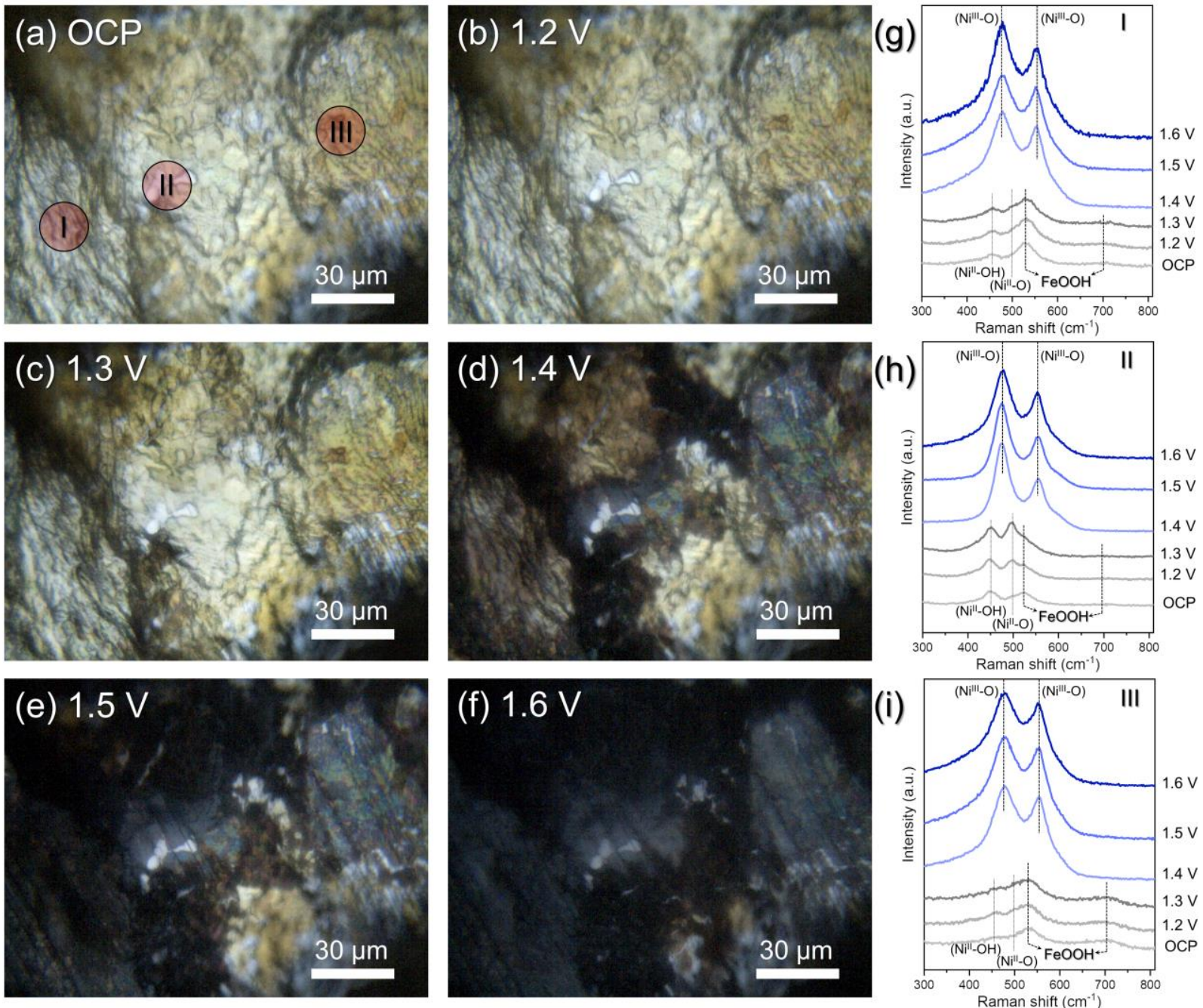

Figure 3. Operando Raman spectroscopic analysis. (a-f) Optical microscopy images of FeOOH-NiOOH at given potentials and (gi) the corresponding operando Raman spectra obtained from three different spots as indicated in the (a).

\subsection{Operando Raman spectroscopic data 2.2.1 Spectral features}

Figurez shows operando Raman optical microscopy images and spectra of $\mathrm{FeOOH}-\mathrm{NiOOH}$, recorded from the open circuit potential (OCP) to $1.6 \mathrm{~V}$ (vs. RHE) with an interval of o.1 $\mathrm{V}$. Due to $\mathrm{FeOOH}$, the surface looks brownish-yellow at OCP compared with bare NF (Figure S11), which is silver-white.19, 27 The microscope objective collected Raman signals from three different beam spots (I, II, and III in Figure 3a). The surface gradually turned into black from $1.4 \mathrm{~V}$ (Figure $3 \mathrm{~b}-\mathrm{f}$ ), indicative of the formation of Fe-doped $\mathrm{NiOOH}$ support. $28-29$ The potential-dependent Raman spectra vary at three different spots of the surface (Figure $3 \mathrm{~g}-\mathrm{i}$ ), indicating a surface heterogeneity. Indeed TEM and EDX mapping images (Figure $\mathrm{S}_{4}$ and $\mathrm{S}_{5}$ ) showed that Fe ions were not uniformly distributed on the surface. Consistent with previous XAS results, ${ }^{19}$ surface $\gamma$ $\mathrm{FeOOH}$ species were identified by two main Raman bands at $526 \mathrm{~cm}^{-1}$ and $690 \mathrm{~cm}^{-1}$ (Figure 3g-i and S12).19, 30-31 At $1.4 \mathrm{~V}$ and above, two strong Raman bands at around 480 and $560 \mathrm{~cm}^{-1}$ 
were observed (Figure 3g-i). These two bands correspond to the Ni-O bending and stretching vibrations of $\mathrm{NiOOH}$, respectively. .22 , 32-35 Their appearance indicated the presence of $\mathrm{NiOOH}$ at these potentials, again consistent with previous XAS data. 19 At the three chosen spots on the surface, the relative intensities of the $480 \mathrm{~cm}^{-1}$ and $560 \mathrm{~cm}^{-1}$ bands $\left(\mathrm{I}_{\mathrm{B}} / \mathrm{I}_{\mathrm{S}}\right)$ and the half-widths of the two bands vary, indicating different local environments around the Ni-O bonds. Fe-incorporation into $\mathrm{NiOOH}$ causes structural defects and disorder of lattice, which leads to a lower $\mathrm{I}_{\mathrm{B}} / \mathrm{I}_{\mathrm{S}}$. $\underline{22}$, 32, 35 Accordingly, the amount of Fe dopant in the $\mathrm{NiOOH}$ at the three spots follows the order of: III > I > II. A broad band in the frequency range of 900 to $1150 \mathrm{~cm}^{-1}$, previously attributed to $\mathrm{Ni}-\mathrm{OO}^{-}, 32-34,36$ was observed from 1.375 V (Figure Siza).

The Operando Raman spectra collected of NiFe LDH from OCP to $1.5 \mathrm{~V}$ (Figure S13b) show no spectral features corresponding to $\gamma$-FeOOH. Compared to $\mathrm{Ni} \mathrm{LDH}$ and pure NF, $\mathrm{NiFe} \mathrm{LDH}$ exhibits a peak corresponding to $\mathrm{Ni}(\mathrm{II})-\mathrm{O}$ vibration at around $530 \mathrm{~cm}^{-1}$ but not $500 \mathrm{~cm}^{-1}$, which originates from the structural disorder induced by Fe doping. (Figure S13b and $\mathrm{S} 14$ ). 30, 35, 37 The two Raman bands of Ni(III)-O (from NiOOH) began to grow from $1.375 \mathrm{~V}$ and the growth was completed at around $1.45 \mathrm{~V}$ (Figure S13b). The broad band in higher frequency range of 900 to $1150 \mathrm{~cm}^{-1}$, due to $\mathrm{Ni}^{-\mathrm{OO}^{-}, 32-34,36}$ appeared from about 1.4 V.(Figure $\mathrm{S}_{13} \mathrm{~b}$ ).

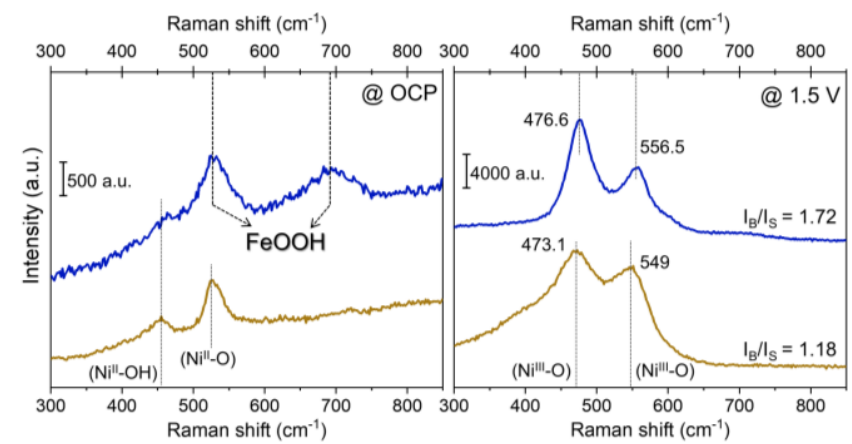

Figure 4. Operando Raman spectra of $\mathrm{FeOOH}-\mathrm{NiOOH}$ (blue) and $\mathrm{NiFe} \mathrm{LDH}$ (brown) recorded at OCP (left) and $1.5 \mathrm{~V}$ (right).

We compare directly the representative Raman spectra of FeOOH-NiOOH and $\mathrm{NiFe} \mathrm{LDH}$ at OCP and 1.5 V (Figure 4). At OCP, Ni is mostly in the +2 oxidation state, and the $\mathrm{Ni}^{\mathrm{II}}-\mathrm{O}$ bands have low intensities (Figure 4a). Accordingly, Raman bands due to $\mathrm{FeOOH}$ could be observed (Figure 4a). The presence of $\mathrm{FeOOH}$ in $\mathrm{FeOOH}-\mathrm{NiOOH}$, but not $\mathrm{NiFe} \mathrm{LDH}$, was obvious. At $1.5 \mathrm{~V}, \mathrm{NiOOH}$ is formed where $\mathrm{Ni}$ is in the oxidation state of +3 , and the $\mathrm{Ni}^{\mathrm{III}}-\mathrm{O}$ bands have high intensities (Figure $4 \mathrm{~b}$ ). The $\mathrm{I}_{\mathrm{B}} / \mathrm{I}_{\mathrm{S}}$ of NiFe LDH (1.18) was significantly lower than that of $\mathrm{FeOOH}-\mathrm{NiOOH}(1.72)$, bare NF (1.91), and Ni LDH (2.2) (Figure S15), indicative of the highest structural disorder of NiFe LDH among the four samples. Because this NiFe LDH sample contains $20 \%$ whereas $\mathrm{FeOOH}-\mathrm{NiOOH}$ has an Fe content of about $10 \%$ in some region (Figure $\mathrm{S}_{3}$ ), Raman spectra were also recorded for a NiFe LDH with 10\% Fe (Figure S16, EDX mapping images and CVs of this catalyst are in Figure $\mathrm{S}_{17}-\mathrm{S}_{18} 8$ ). The $\mathrm{I}_{\mathrm{B}} / \mathrm{I}_{\mathrm{s}}$ of $\mathrm{NiFe} \mathrm{LDH}(10 \% \mathrm{Fe})$ was 1.33 , again lower than that of $\mathrm{FeOOH}-\mathrm{NiOOH}$.
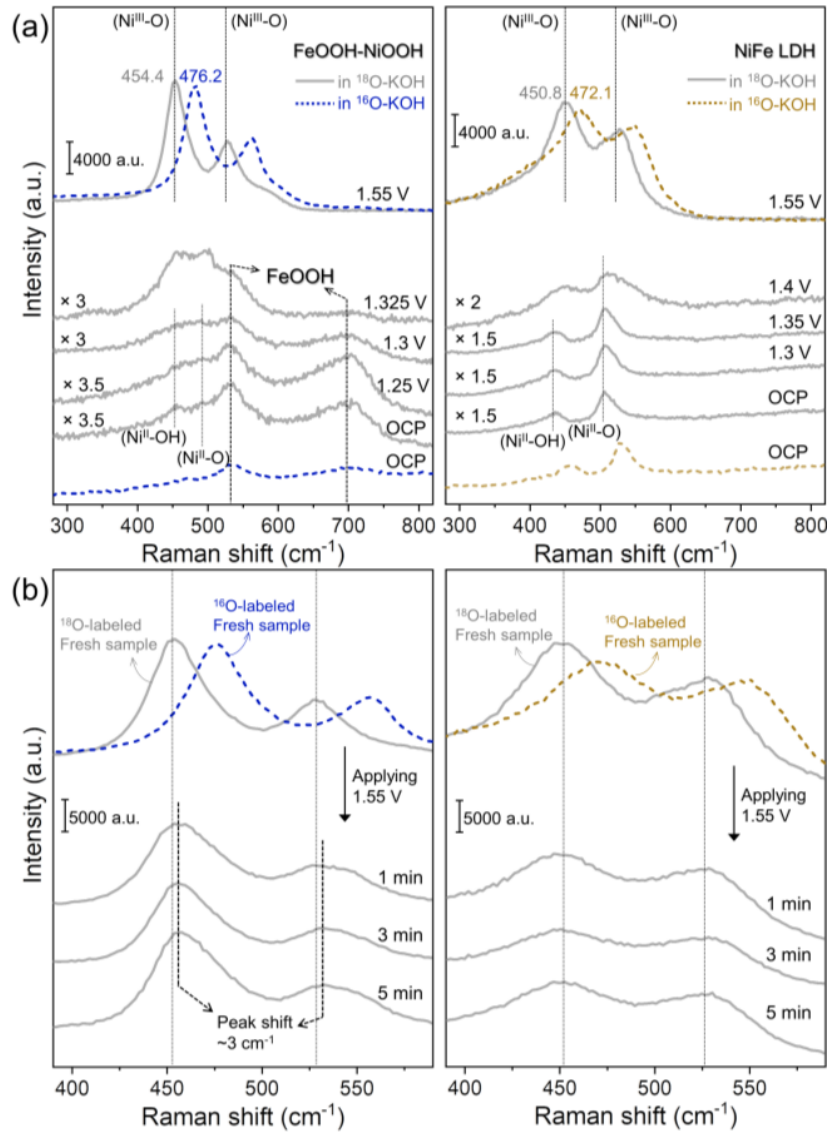

Figure 5. Operando Raman spectra of $\mathrm{FeOOH}-\mathrm{NiOOH}$ (left column) and NiFe LDH (right column) obtained at various potentials for oxygen isotope labeling (a) in $1 \mathrm{M} \mathrm{KOH}-\mathrm{H}_{2}{ }^{18} \mathrm{O}$ solution and (b) subsequent isotope exchange experiments. The ${ }^{18} \mathrm{O}$-labeled samples were monitored at $1.55 \mathrm{~V}$ in $1 \mathrm{M} \mathrm{KOH}-$ $\mathrm{H}_{2}{ }^{16} \mathrm{O}$ solution. For ease of comparison of peak shift in between the two solutions, ${ }^{16} \mathrm{O}$-labeled peaks of each sample are indicated respectively.

\subsubsection{Oygen isotope exchange experiments}

We conducted ${ }^{18} \mathrm{O}$ isotope labeling and exchange experiments on FeOOH-NiOOH and NiFe LDH. The as-prepared, ${ }^{16} \mathrm{O}$-labeled, samples were first immersed in a ${ }^{18} \mathrm{O}$ $\mathrm{KOH}$ solution. For FeOOH-NiOOH at OCP to about $1.3 \mathrm{~V}$, the peak of $\mathrm{FeOOH}$ remained at the same position whereas the peaks of $\mathrm{Ni}^{\mathrm{II}}-\mathrm{O}, \mathrm{Ni}^{\mathrm{II}}-\mathrm{OH}$ appeared to be shifted, but the shift could not be quantified due to an overlap of peaks.(Figure 5a, left) For NiFe LDH same as reported previously, ${ }^{32-33}$ the peaks of $\mathrm{Ni}^{\mathrm{II}}-\mathrm{O}, \mathrm{Ni}^{\mathrm{II}}-\mathrm{OH}$ at $\mathrm{OCP}$ to about 1.35 $\mathrm{V}$ red-shifted by about $22 \mathrm{~cm}^{-1}$, indicating the exchange of lattice ${ }^{16} \mathrm{O}$ with ${ }^{18} \mathrm{O}$ of the electrolyte (Figure 5a, right). Upon formation of $\mathrm{NiOOH}$, and more obviously at $1.55 \mathrm{~V}$, the $\mathrm{Ni}^{\mathrm{III}} \mathrm{O}$ bands were observed at around 455 and $535 \mathrm{~cm}^{-}$ ${ }^{1}$ for both $\mathrm{FeOOH}-\mathrm{NiOOH}$ and $\mathrm{NiFe} \mathrm{LDH}$, red-shifted by about $22 \mathrm{~cm}^{-1}$ relative to those of ${ }^{16} \mathrm{O}$-labeled samples. This shift indicates $\mathrm{O}$ isotope exchange. For $\mathrm{FeOOH}-\mathrm{NiOOH}$, the Raman peaks of $\gamma$-FeOOH did not shift during this process up to $1.325 \mathrm{~V}$. At higher potentials the peaks were hidden by those of $\mathrm{Ni}^{\mathrm{III}}-\mathrm{O}$ bands. To probe whether lattice $\mathrm{O}$ in $\mathrm{FeOOH}$ was exchanged during OER, a FeOOH-NiOOH 
sample was first subjected to a ${ }^{18} \mathrm{O}-\mathrm{KOH}$ solution at $1.55 \mathrm{~V}$ where OER was occurring, and then the Raman spectrum was collected at $1.25 \mathrm{~V}$. Again the Raman peaks of $\gamma-\mathrm{FeOOH}$ remained at the same positions of a ${ }^{16} \mathrm{O}$-labeled sample (Figure S19). Thus, the lattice oxygens of $\gamma$-FeOOH do not exchange with the electrolyte even under OER.

The ${ }^{18} \mathrm{O}$-labeled samples of FeOOH-NiOOH and NiFe LDH were immediately placed back in a $1 \mathrm{M}^{16} \mathrm{O}-\mathrm{KOH}$ solution and potentiostatically charged at $1.55 \mathrm{~V}$. For $\mathrm{FeOOH}-$ $\mathrm{NiOOH}$, the peaks corresponding to $\mathrm{Ni}^{\mathrm{III}}-\mathrm{O}$ vibrational modes were shifted by about $3 \mathrm{~cm}^{-1}$ to high frequencies (Figure $5 \mathrm{~b}$, left). For NiFe LDH, no shift of peaks related to $\mathrm{Ni}^{\mathrm{III}}-\mathrm{O}$ was observed (Figure $5 \mathrm{~b}$, right). As a reference, a shift of $18 \mathrm{~cm}^{-1}$ was observed on bare NF (Figure S2o).

\subsection{Electrokinetic data}

FeOOH-NiOOH exhibited a similar Tafel Slope of $38 \pm 2$ $\mathrm{mV} / \mathrm{dec}$ in $0.5 \mathrm{M}$ to $2 \mathrm{M} \mathrm{KOH}$ (Figure 6a, S21a, Table $\mathrm{S} 1$ ). The potentials vs. $\mathrm{Ag} / \mathrm{AgCl}$ ( $\mathrm{pH}$ independent) at $10 \mathrm{~mA} / \mathrm{cm}^{2}$ linearly depended on the log of the concentration of hydroxyl ions (Figure $6 \mathrm{~b}$ ), with a slope of $-74 \mathrm{mV} / \mathrm{dec}$. The rate order of $\left[\mathrm{OH}^{-}\right]$in $0.5-2 \mathrm{M} \mathrm{KOH}$ was determined according to Eq. 1 .

$$
\left(\frac{\partial \log j}{\partial \log \left[O H^{-}\right]}\right)_{E}=-\frac{\left(\frac{\partial E}{\partial \log \left[O H^{-}\right]}\right)_{j}}{\left(\frac{\partial E}{\partial \log j}\right)_{p H}} \quad \text { Eq. } 1
$$
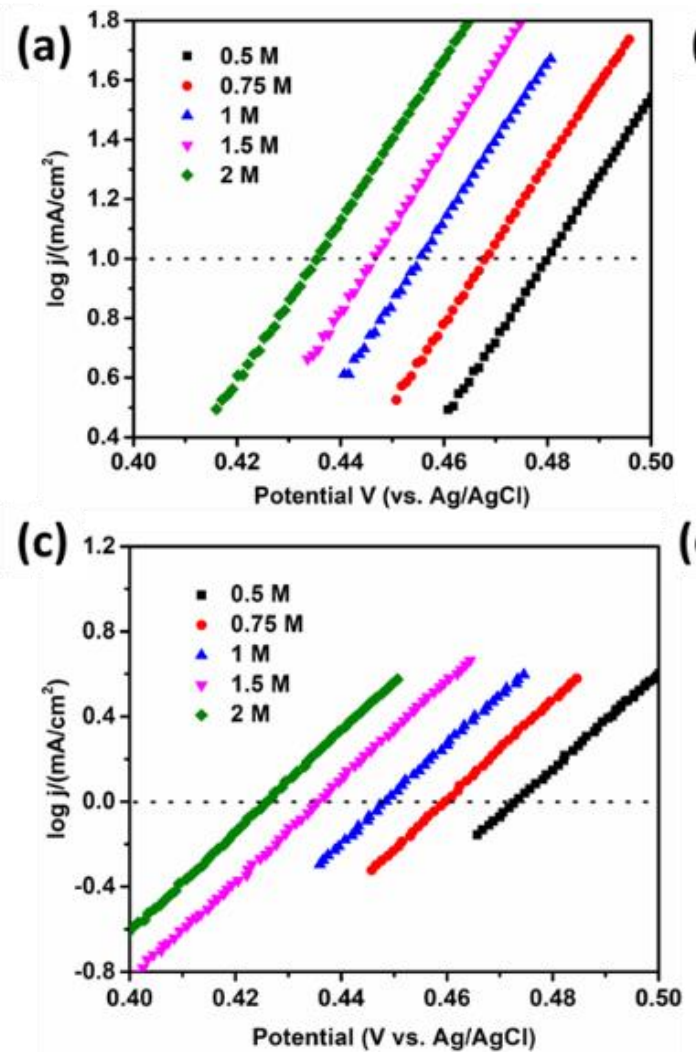

(d)
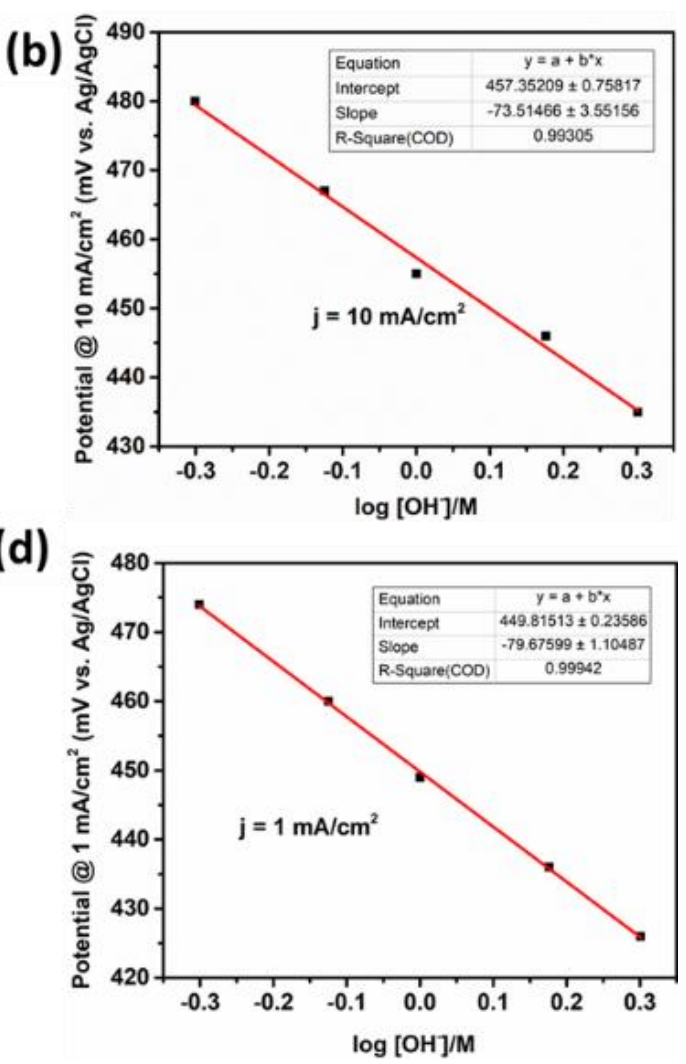

Figure 6. Electrokinetic analysis. (a) and (b) for FeOOH-NiOOH. (c) and (d) for NiFe-LDH. (a) and (c) The Tafel plots in different concentrations of $\mathrm{KOH}$. The original LSVs are provided in SI. (b) and (d) The change of constant potential at a certain current density $\left(10 \mathrm{~mA} / \mathrm{cm}^{2}\right.$ for FeOOH-NiOOH and $1 \mathrm{~mA} / \mathrm{cm}^{2}$ for $\left.\mathrm{NiFe} \mathrm{LDH}\right)$ based on the logarithm of $\left[\mathrm{OH}^{-}\right]$. The linear fitting of the data points gives the $\left(\partial \mathrm{E} / \partial \log \left[\mathrm{OH}^{-}\right]\right)_{j}$ values, as the slope of the fitting plot.

The OER activity of FeOOH-NiOOH had an H/D isotope effect of 1.4 to 2.0, depending on the concentration of hydroxyl ions and the applied potential (Figure 7a, S24a, 
S25a). On the other hand, NiFe LDH had an H/D isotope effect of 2.0-2.4 (Figure 7b, S24b, S25b), and the isotope effect did not vary substantially at different potentials nor $\left[\mathrm{OH}^{-}\right]$.
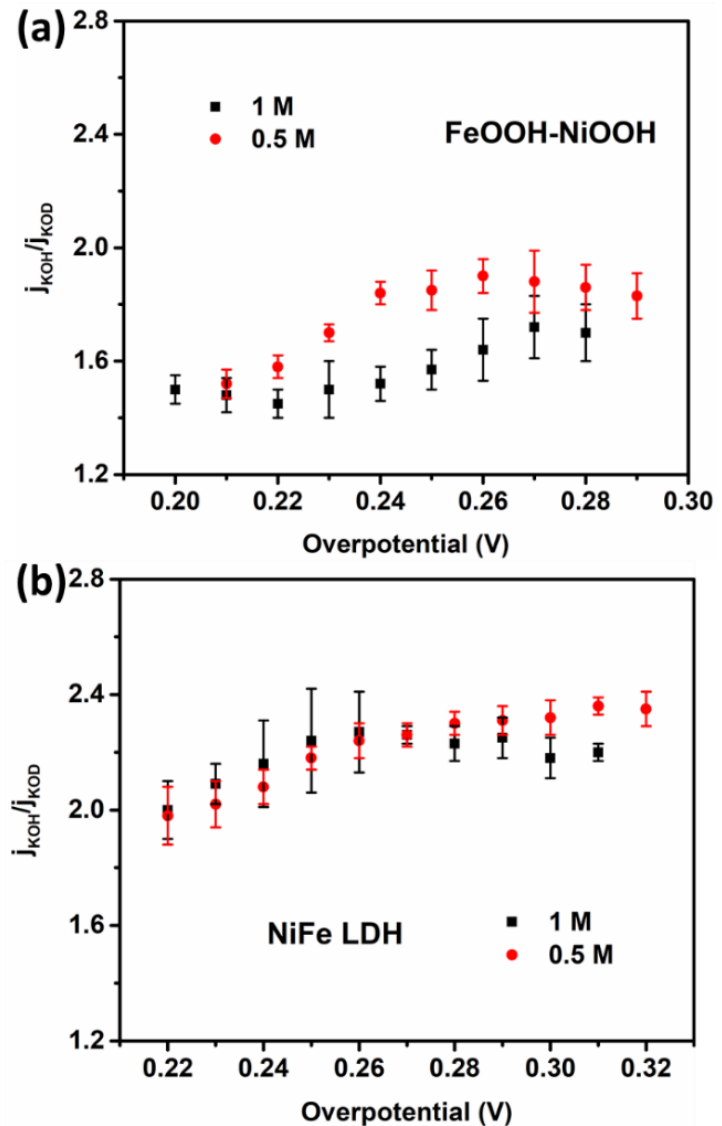

Figure 7. H/D isotope effect analysis $\left(\mathrm{j}_{\mathrm{KOH}} / \mathrm{j}_{\mathrm{KOD}}\right.$ versus overpotential). (a) NiFe LDH and (b) $\mathrm{FeOOH}-\mathrm{NiOOH}$. Electrolyte concentrations: $1 \mathrm{M}$ (black), $0.5 \mathrm{M}$ (red). The error bar and the average values were deduced from 3 independent measurements.

\section{Discussion}

\subsection{Raman spectroscopic analysis}

Operando Raman spectra revealed the presence of surface $\gamma$-FeOOH in FeOOH-NiOOH, but not in NiFe LDH. Otherwise the two catalysts have a similar component, Fedoped $\gamma-\mathrm{NiOOH}$. Bulk $\gamma$-FeOOH is a poor OER catalyst, $\underline{23}$, $3^{8}$ whereas the surface $\gamma$-FeOOH here is responsible for remarkable OER activity (Figure 2, and S10). This difference suggests a mechanism that involves more than $\gamma$-FeOOH alone. The doping of $\mathrm{Fe}$ in $\mathrm{NiOOH}$ causes structural disorder in the lattice of $\mathrm{NiOOH}$, which could be inferred by the $\mathrm{I}_{\mathrm{B}} / \mathrm{I}_{\mathrm{S}}$ of the Raman spectra of $\mathrm{NiOOH} .22,32,35$ The lower structural disorder of $\mathrm{FeOOH}-\mathrm{NiOOH}$ compared to NiFe $\mathrm{LDH}$ is consistent with most Fe ions being on the surface in $\mathrm{FeOOH}-\mathrm{NiOOH}$ but in the bulk of NiFe LDH.

As reported previously, $32-33$ the lattice $\mathrm{O}$ of $\mathrm{NiOOH}$ in $\mathrm{NiFe}$ $\mathrm{LDH}$ can exchange with $\mathrm{O}$ from the $\mathrm{OH}^{-}$electrolyte. The exchange can occur without applying a potential when $\mathrm{Ni}$ is at the +2 oxidation state (as in $\mathrm{Ni}(\mathrm{OH})_{2}$ ), but not when $\mathrm{Ni}$ is oxidized to +3 or above. The lattice $\mathrm{O}$ of $\mathrm{NiOOH}$ in $\mathrm{FeOOH}-\mathrm{NiOOH}$ can also be exchanged at the $\mathrm{Ni}^{\mathrm{II}}$ stage. Under OER potentials, a $3 \mathrm{~cm}^{-1}$ isotopic shift of $\mathrm{FeOOH}-$ $\mathrm{NiOOH}$ indicates partial $\mathrm{O}$ exchange. Compared to bulk NF $\left(18 \mathrm{~cm}^{-1}\right.$ shift), the exchange is about $16 \%$. The different $\mathrm{O}$ exchange behavior reflects a mechanistic difference between $\mathrm{FeOOH}-\mathrm{NiOOH}$ and $\mathrm{NiFe}$ LDH.

\subsection{Electrokinetic analysis}

\subsubsection{Tafel slope and rate order}

We employed a quasi-equilibrium model to describe the OER kinetics, in which the key steps are described by one pre-equilibrium step (PES) plus one rate-determining step (RDS). ${ }^{39-40}$ The RDS limits the OER velocity while the PES determines the concentration of the resting states. The overall OER rate and catalytic behavior are controlled by both steps. The other steps are fast and do not restrict overall reaction rate. This model is suitable for catalysts in the intermediate applied overpotential (Tafel region), where the concentration of the resting state is not high (see Appendix 1, SI).

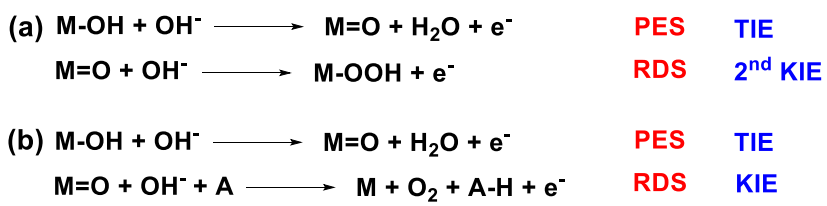

Scheme 1. (a) General key steps of the traditional OER mechanism in alkaline medium. ${ }^{-}$(b) General key steps of the bifunctional OER mechanism in alkaline medium. .9

For the conventional mechanism involving four PCET steps (Figure 1a), if the formation of $\mathrm{M}=\mathrm{O}$ is the PES, and the nucleophilic attack of $\mathrm{OH}^{-}$on a $\mathrm{M}=\mathrm{O}$ is the $\mathrm{RDS}$ (Scheme 1a), the predicted Tafel slope is $40 \mathrm{mV} / \mathrm{dec}$ and the predicted rate order in $\left[\mathrm{OH}^{-}\right]$is two, assuming there is no charge transfer barrier. ${ }^{40-41}$ For the bifunctional mechanism (Figure 1c), if the formation of $\mathrm{M}=\mathrm{O}$ is the PES, and the nucleophilic attack of $\mathrm{OH}^{-}$on a $\mathrm{M}=\mathrm{O}$ coupled with a hydrogen atom transfer is the RDS (Scheme $1 \mathrm{~b}$ ), the predicted Tafel slope is also $40 \mathrm{mV} / \mathrm{dec}$ and the predicted rate order in $\left[\mathrm{OH}^{-}\right]$is also two (Appendix 1, SI). The experimental values for both $\mathrm{FeOOH}-\mathrm{NiOOH}$ and $\mathrm{NiFe} \mathrm{LDH}$, thus, agree with the predictions of both mechanisms. However, there are noticeable differences in the Tafel behaviors of $\mathrm{FeOOH}-\mathrm{NiOOH}$ and $\mathrm{NiFe} \mathrm{LDH}$. The Tafel slopes of $\mathrm{FeOOH}-\mathrm{NiOOH}$ is independent of $\left[\mathrm{OH}^{-}\right]$. In contrast, the Tafel slope of NiFe LDH decreases with increasing $\left[\mathrm{OH}^{-}\right]$, suggesting a charge transfer barrier across the bulk film, which is more pronounced at lower $\left[\mathrm{OH}^{-}\right]$(for a detailed description, see SI, Appendix 1). ${ }^{42-43}$ The absence of charge transfer barrier in $\mathrm{FeOOH}-\mathrm{NiOOH}$ would be consistent with surface-dominated catalysis. The significant cation effect for NiFe LDH also indicates bulk sites are involved in OER, ${ }^{44-46}$ although the origin of this effect is under debate. ${ }^{44-46}$ The small cation effect observed for $\mathrm{FeOOH}-$ $\mathrm{NiOOH}$ is again consistent with surface catalysis. 


\subsubsection{H/D isotope effect}

H/D exchange affects both thermodynamics and kinetics of PCET reactions. ${ }^{47-48}$ Accordingly, both thermodynamic isotope effect (TIE) and the kinetic isotope effect (KIE) exist. ${ }^{47-48}$ The TIE originates from a change in the reaction thermodynamics due to different vibrational zero-point energies (ZPEs) of bonds involving hydrogen and deuterium. ${ }^{47}, 49$ In the present case, H/D TIE effect should be observed in PES involving proton transfer. On the other hand, H/D KIE originates from the different activation barriers caused by the differences of ZPEs between $\mathrm{H}$ - and and D-substituted analogues. ${ }^{47-48}, 50-51$. KIE is usually employed to probe the involvement of proton transfer in RDS. $47-48$, 5051 The combination of TIE and KIE leads to the overall observed isotope effect (IE).

For the conventional mechanism (Figure ra and Scheme 1a), there is direct proton transfer in the PES but not in RDS. Consequently, only TIE and secondary KIE are expected. Secondary KIE is typically below 1.3, ${ }^{50}, 52$ so TIE would dominate. The data for NiFe LDH (H/D IE of 2.02.4) fit this model. The IE is roughly independent of applied potential, characteristic of TIE. ${ }^{15}, 49$ Moreover, the IE is $\mathrm{pH}$-independent, consistent with a PCET-type PES. ${ }^{15}, 49$

For the bifunctional mechanism, the direct proton/hydrogen transfer is involved in both PES and RDS (Figure 1c and Scheme $1 \mathrm{~b}$ ), so that KIE becomes significant. In the Tafel region, the overall IE can be expressed as Eq. 2 (Appendix 2 of SI). 50

$I E=\frac{k_{0}}{k_{0}^{\prime}} \exp \left(\frac{\left(\alpha_{2}-\alpha_{2}^{\prime}\right) \eta F}{R T}\right)$

$\mathrm{k}_{\mathrm{o}}$ and $\mathrm{k}_{\mathrm{o}}{ }^{\prime}$ are the rate constants of $\mathrm{H}$ - and D-substituted reactants, respectively; $\alpha_{2}$ and $\alpha_{2}{ }^{\prime}$ are the transfer coefficients of RDS for $\mathrm{H}$ - and D-substituted reactants; $\mathrm{R}, \mathrm{T}, \eta$, and $\mathrm{F}$ are universal gas constant, thermodynamic temperature, overpotential, Faradaic constant, respectively. Typically $\alpha_{2}$ is bigger than $\alpha_{2}{ }^{\prime}$ due to a higher barrier of charge transfer after D-substitution. ${ }^{50}$ In the Tafel region, $k_{o}$ and $\mathrm{k}_{\mathrm{o}}{ }^{\prime}, \alpha_{2}$ and $\alpha_{2}{ }^{\prime}$ can be considered potential-independent. Therefore, the observed IE should increase with increasing overpotential. Moreover, if the generation of the hydrogen atom acceptor is $\mathrm{pH}$-dependent, the KIE is expected to depend on $\mathrm{pH}$ as well. 53 The data for $\mathrm{FeOOH}-\mathrm{NiOOH}$ fit this model. The observed isotopic effect indeed increases with applied overpotential, and decreases with $\left[\mathrm{OH}^{-}\right]$. Note that the overall IE of $\mathrm{FeOOH}-\mathrm{NiOOH}$, dominated by $\mathrm{KIE}$, is lower than that of NiFe LDH, dominated by TIE. Accordingly, the TIE of FeOOH-NiOOH is lower than that of NiFe $\mathrm{LDH}$, reflecting a difference in the nature of $\mathrm{M}=\mathrm{O}$ in these two catalysts. The KIE of FeOOH-NiOOH is rather small likely due to the internal hydrogen transfer in RDS. Previous literatures suggested internal hydrogen or proton acceptor could minimize the $\mathrm{H} / \mathrm{H}^{+}$transfer distance, significantly decreasing the H/D KIE. $54-55$

\subsection{Catalytic cycle}

Based on the above data, we propose a catalytic cycle for FeOOH-NiOOH (Figure 8a). The as-prepared catalyst A-I is composed of $\gamma$-FeOOH clusters covalently linked to a $\mathrm{Ni}(\mathrm{OH})_{2}$ support, which is lightly doped by Fe. At about
1.35 V, the support is oxidized to $\mathrm{NiOOH}$ via a $3 \mathrm{OH}^{-} / 2 \mathrm{e}^{-}$ process. The process is best described by oxidation of a dimeric $\mathrm{Ni}^{\mathrm{II}}$ unit into a dimeric $\mathrm{Ni}^{\mathrm{III}}$ unit accompanied by the loss of three protons from coordinated water or $\mathrm{OH}^{-}$ groups (A-II). The $\mathrm{Fe}^{\mathrm{III}}$ center in $\mathrm{FeOOH}$ then undergoes a PCET to form an electrophilic $\mathrm{Fe}(\mathrm{IV})=\mathrm{O}$ center $(\mathrm{A}-\mathrm{III})$, which is the PES of the catalytic cycle. Consequently and in the RDS, the $\mathrm{Fe}(\mathrm{IV})=\mathrm{O}$ center, an external $\mathrm{OH}^{-}$, and the $\mathrm{Ni}^{\mathrm{III}}-\mathrm{O}$ moiety react in a concerted manner to give $\mathrm{Fe}^{\mathrm{II}}-\mathrm{Ni}^{\mathrm{II}}$ $\mathrm{OH}(\mathrm{A}-\mathrm{IV}), \mathrm{O}_{2}$ and an electron. Oxidations of $\mathrm{Fe}^{\mathrm{II}}$ and $\mathrm{Ni}^{\mathrm{II}}$ then regenerates the catalyst (A-II).

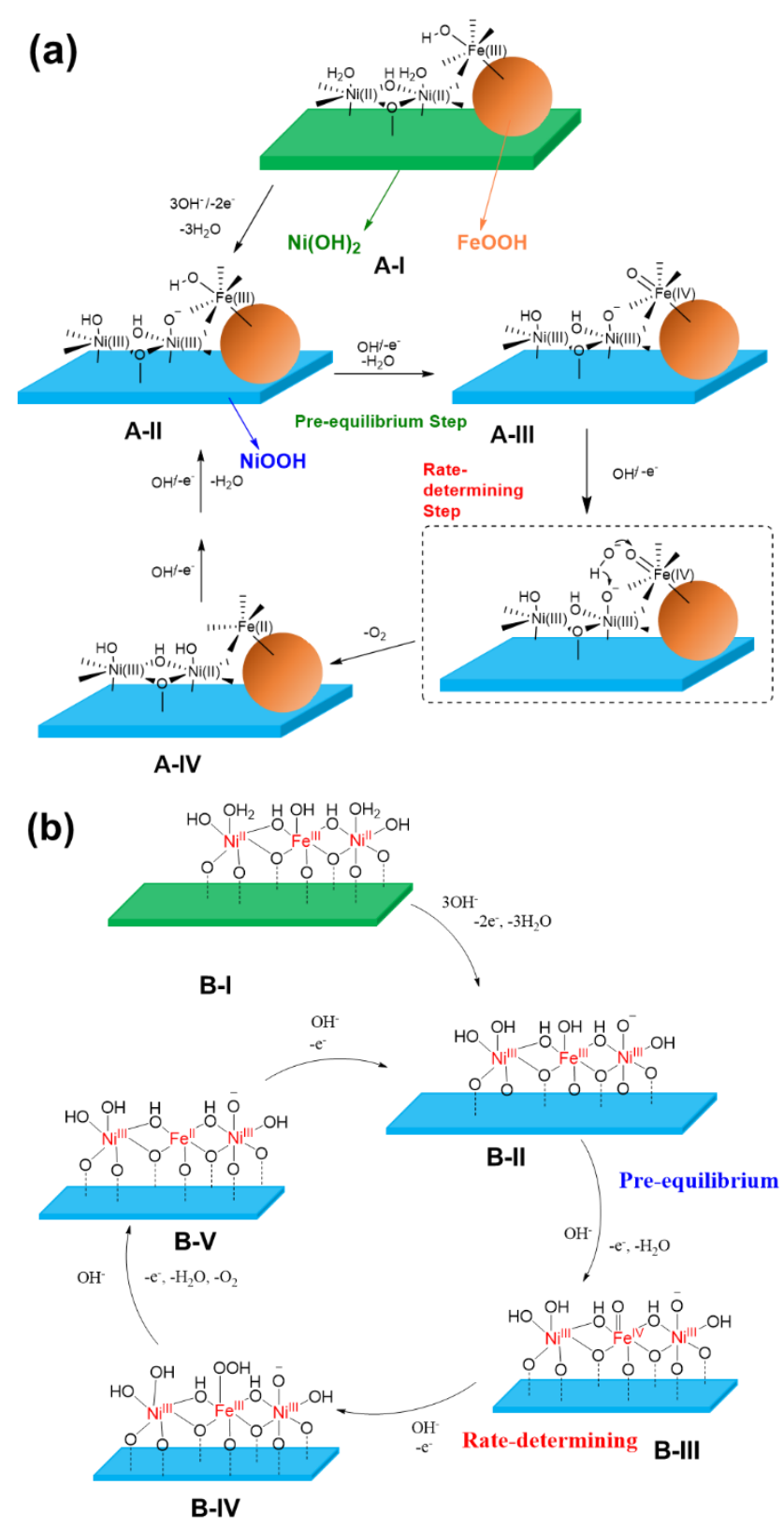

Figure 8. Proposed OER reaction mechanisms of (a) FeOOH$\mathrm{NiOOH}$. (b) NiFe LDH (assuming Fe is the catalytic center).

For NiFe LDH (Figure 8b), the as-prepared catalyst is comprised of $\mathrm{Ni}(\mathrm{OH})_{2}$ doped by $\mathrm{Fe}^{\mathrm{III}}$ ions (B-I). A $3 \mathrm{OH}^{-} / 2 \mathrm{e}^{-}$process generates Fe-doped $\mathrm{NiOOH}(\mathrm{B}-\mathrm{II})$. Although there are 
debates on whether $\mathrm{Ni}$ or Fe site serves as the site of $\mathrm{O}-\mathrm{O}$ bond formation, 3, 23, 56 a dimeric $\mathrm{Fe}-\mathrm{O}-\mathrm{Ni}$ active site would agree with most data. The catalytic cycle proceeds via a PES to form a $\mathrm{M}=\mathrm{O}$ (B-III, assuming $\mathrm{M}$ is $\mathrm{Fe}$, but the same result is obtained when $\mathrm{M}$ is $\mathrm{Ni}$ ), followed by a $\mathrm{RDS}_{\text {of }} \mathrm{OH}^{-}$attack on $\mathrm{M}=\mathrm{O}$ to give $\mathrm{M}-\mathrm{OOH}$ (B-IV). A further PCET oxidation gives $\mathrm{O}_{2}$ and $\mathrm{M}(\mathrm{B}-\mathrm{V})$, which can then be oxidized back to the initial catalyst B-II. When $\mathrm{M}$ is Fe, the Fe ions shuffle between $\mathrm{Fe}^{\mathrm{II}}$, $\mathrm{Fe}^{\mathrm{III}}$, and $\mathrm{Fe}^{\mathrm{IV}}$ while the $\mathrm{Ni}$ ions remain as $\mathrm{Ni}^{\mathrm{III}}$ during catalysis. When $\mathrm{M}$ is $\mathrm{Ni}$, the $\mathrm{Ni}$ ions shuffle between $\mathrm{Ni}^{\mathrm{II}}, \mathrm{Ni}^{\mathrm{III}}$, and $\mathrm{Ni}^{\mathrm{IV}}$ while the $\mathrm{Fe}$ ions remain as $\mathrm{Fe}^{\mathrm{III}}$.

The results from $\mathrm{O}$ isotope exchange experiments (Figure 5 b) suggest the presence of transient $\mathrm{Ni}^{\mathrm{II}}$ sites in $\mathrm{FeOOH}$ $\mathrm{NiOOH}$ but not NiFe LDH during OER. About $16 \%$ of lattice $\mathrm{O}$ in $\mathrm{FeOOH}-\mathrm{NiOOH}$ exchanges with $\mathrm{OH}^{-}$under OER, but such an exchange is absent in NiFe LDH. It is known that at $\mathrm{Ni}^{\mathrm{II}}$ the lattice $\mathrm{O}$ of $\mathrm{Fe}$-doped $\mathrm{NiOOH}$ and $\mathrm{NiFe} \mathrm{LDH}$ can exchange with $\mathrm{O}$ from $\mathrm{OH}^{-}$electrolyte without applied potential, but at $\mathrm{Ni}^{\mathrm{III}}$ and above, the exchange does not occur even under OER. ${ }^{22-33}$ These results are consistent with FeOOH-NiOOH operating via the bifunctional mechanism (Figure $8 \mathrm{a}$ ) where a $\mathrm{Ni}^{\mathrm{III}}-\mathrm{O}$ site accepts a hydrogen atom in the RDS to become a Ni ${ }^{\mathrm{II}}-\mathrm{OH}$ site. They are also consistent with $\mathrm{NiFe} \mathrm{LDH}$ operating via the conventional mechanism (Figure $8 \mathrm{~b}$ ) where the redox changes occur at the Fe site.

\section{Conclusion}

Operando Raman spectroscopy and electrokinetic analysis were employed to study two active OER catalysts, FeOOH$\mathrm{NiOOH}$ and $\mathrm{NiFe}$ LDH. Despite their similar chemical compositions, the two catalysts exhibit different electrochemical and spectroscopic features, which indicate that most Fe ions exist in surface $\gamma$-FeOOH clusters in FeOOH$\mathrm{NiOOH}$ but they are doped in the lattice of $\mathrm{Ni}(\mathrm{OH})_{2} / \mathrm{NiOOH}$ in NiFe LDH. This different results in a 10-fold higher OER activity of $\mathrm{FeOOH}-\mathrm{NiOOH}$ compared to $\mathrm{NiFe}$ LDH. During OER, different $\mathrm{O}$ isotope exchange behaviors of the $\mathrm{NiOOH}$ component were observed for the two catalysts: about $16 \%$ of lattice $\mathrm{O}$ in $\mathrm{FeOOH}-\mathrm{NiOOH}$ exchanged with the $\mathrm{OH}^{-}$electrolyte whereas there was no exchange for $\mathrm{NiFe} \mathrm{LDH}$. These data suggest that $\mathrm{Ni}^{\mathrm{II}}$ species are present in the catalytic cycle of $\mathrm{FeOOH}-\mathrm{NiOOH}$, but not NiFe LDH. The two catalysts exhibit similar Tafel slopes and rate orders in $\left[\mathrm{OH}^{-}\right]$under standard conditions. However, they have different $\mathrm{H} / \mathrm{D}$ isotope effects. FeOOH$\mathrm{NiOOH}$ has an IE of 1.4 to 2.0, which had a significant KIE component and depend on $\left[\mathrm{OH}^{-}\right]$and the overpotential. NiFe LDH had an IE of 2.0-2.4, which is mostly TIE and is independent of $\left[\mathrm{OH}^{-}\right]$and the overpotential. The spectroscopic and kinetic data support two distinct mechanisms for the two catalysts. FeOOH-NiOOH operates by a bifunctional mechanism where the rate-determining $\mathrm{O}-\mathrm{O}$ bond forming step is the concerted $\mathrm{OH}$ - attack on a $\mathrm{Fe}=\mathrm{O}$ coupled with a hydrogen atom transfer to a $\mathrm{Ni}^{\mathrm{III}}-\mathrm{O}$ site. On the contrary, NiFe LDH operates by a conventional mechanism of four consecutive PCET steps, and the rate-determining $\mathrm{O}-\mathrm{O}$ bond forming step is the attack of $\mathrm{OH}^{-}$on a $\mathrm{Fe}=\mathrm{O}$ unit.
The data describe here constitute the first experimental evidences for the bifunctional mechanism which has hitherto only computational supports. The superior activity of $\mathrm{FeOOH}-\mathrm{NiOOH}$ demonstrates the potential of bifunctional catalysts to overcome the performance limit of conventional catalysts imposed by the scaling relationship. The bifunctional mechanism provide an opportunity to individually fine-tune two components of an OER catalyst for optimized activity, adding a new design principle. For example, analogous to the present $\mathrm{FeOOH}-\mathrm{NiOOH}$ catalyst, the FeOOH component might be replaced by another material with a low energy barrier to form an electrophilic $\mathrm{M}=\mathrm{O}$ unit, while the $\mathrm{NiOOH}$ component might be replaced by another hydrogen atom acceptor, including even organic materials.

\section{Experimental Sections}

\subsection{Chemicals and the synthesis of the catalysts}

$\mathrm{KOD}\left(30 \%\right.$ in $\left.\mathrm{D}_{2} \mathrm{O}\right)$ is purchased from $\mathrm{ABCR}$; ethanol (99.5\%) is purchased from Fluka; $1 \mathrm{M} \mathrm{KOH}$ standard solution is purchased from Merck KGaA. All other chemicals were purchased from Sigma-Aldrich. The electrolytes were prepared by using ultra-pure water (18.2 $\mathrm{M} \Omega / \mathrm{cm}$ ).

Pretreatment of nickel foam (NF) The NF was first cleaned by sonicating in acetone for 30 mins to remove the organic impurities. Then the NF was dried and dipped in $15 \% \mathrm{HCl}$ for 30 mins with sonication. The electrode was washed by ultra-pure water and dried in room temperature. Noted that the electrode should be used within two hours, else the surface generated nickel hydroxide would decrease the adsorption ability of the catalysts $(\mathrm{FeOOH})$.

Synthesis of FeOOH-NiOOH ${ }^{19}$ A cleaned NF electrode was dipped in $10 \mathrm{mM} \mathrm{FeCl}_{3}$ solution with stirring for 15 mins. After that, the electrode was directly dried in $75^{\circ} \mathrm{C}$ oven over night. The FeOOH-NiOOH was formed during the drying period.

Synthesis of NiFe LDH (20\% Fe) We used a method according to previous literature with modifications. $\underline{26}$ Typically, $\mathrm{Ni}\left(\mathrm{NO}_{3}\right)_{2} \cdot 6 \mathrm{H}_{2} \mathrm{O}$ (2.0 mmol, $582 \mathrm{mg}$ ), $\mathrm{Fe}\left(\mathrm{NO}_{3}\right)_{3} \cdot{ }^{\circ} \mathrm{H}_{2} \mathrm{O}$ (0.5 mmol, $202 \mathrm{mg}$ ), $\mathrm{NH}_{4} \mathrm{~F}$ (10 mmol, $371 \mathrm{mg}$ ) and urea ( $25 \mathrm{mmol}, 1.50 \mathrm{~g}$ ) were dissolved in $\mathrm{H}_{2} \mathrm{O}(40$ $\mathrm{ml}$ ) with vigorous stirring. The mixed solution was stirred for $30 \mathrm{mins}$ and then transferred to a $50 \mathrm{~mL}$ Teflon-lined stainless steel autoclave. The autoclave was heated at $120{ }^{\circ} \mathrm{C}$ for $16 \mathrm{~h}$. After cooling down to room temperature, the yellowish solid was washed by ultrapure water for 3 times and ethanol for 1 time, and then naturally dried on a watch glass. If no special indication, the NiFe LDH samples mentioned in SI and main-text have $20 \%$ Fe content.

Synthesis of NiFe LDH ( $10 \% \mathrm{Fe})$ The synthetic procedure is a bit different to that of $20 \%$ Fe samples. Typically, the $40 \mathrm{~mL}$ DI water was degassed for $1 \mathrm{~h}$, before dissolving $\mathrm{Ni}\left(\mathrm{NO}_{3}\right)_{2} \cdot 6 \mathrm{H}_{2} \mathrm{O}(2.25 \mathrm{mmol}, 654$ $\mathrm{mg}$ ), $\mathrm{FeSO}_{4} \cdot{ }_{7} \mathrm{H}_{2} \mathrm{O}$ (o.25 mmol, $70 \mathrm{mg}$ ), $\mathrm{NH}_{4} \mathrm{~F}$ (10 mmol, $371 \mathrm{mg}$ ) and urea $(25 \mathrm{mmol}, 1.5 \mathrm{~g})$. The mixed solution was stirred for $30 \mathrm{mins}$ under nitrogen. Then the solution was sealed in a $50 \mathrm{~mL}$ Teflon-lined stainless steel autoclave. The autoclave was heated at $120^{\circ} \mathrm{C}$ for $16 \mathrm{~h}$. After cooling down to room temperature, the green solid was washed by ultrapure water for 3 times and ethanol for 1 time, and then naturally dried on a watch glass. The color of the solid will turn to yellow in the air, while the electrochemical property is not influenced by this color change.

Synthesis of Ni LDH The bulk Ni LDH was synthesized through a hydrothermal method. ${ }^{57} \mathrm{o.10} \mathrm{M}$ of $\mathrm{Ni}\left(\mathrm{NO}_{3}\right)_{2} \cdot 6 \mathrm{H}_{2} \mathrm{O}$ and $0.15 \mathrm{M}$ of urea were dissolved in $80 \mathrm{~mL}$ of deionized water that was already boiled to remove dissolved $\mathrm{CO}_{2}$ in it. The mixed solution was sonicated for 30 mins to make it homogeneous. Then, the resulting solution was transferred to a $50 \mathrm{~mL}$ Teflon-lined stainless steel autoclave and heated at 
$190{ }^{\circ} \mathrm{C}$ for $48 \mathrm{~h}$. The as-obtained green product was collected by centrifugation as it washed with ultrapure water for 3 times and ethanol for 1 time.

Synthesis of $\boldsymbol{\gamma}$ - $\mathrm{FeOOH}$ The material was synthesized according to previous literature with modifications.19 Typically, $20 \mathrm{~mL}$ of $0.02 \mathrm{M}$ $\mathrm{Fe}\left(\mathrm{NO}_{3}\right)_{3}$ solution was sealed in a glass container, which was then maintained at $75{ }^{\circ} \mathrm{C}$ for $24 \mathrm{~h}$. After centrifuging and washing with water for 3 times and ethanol for 1 time, yellowish-brown powder was obtained as $\gamma-\mathrm{FeOOH}$

Preparation of Fe-free KOH The Fe-free $\mathrm{KOH}$ was prepared for Operando Raman experiments of pure NF and pure Ni LDH (see below). The Fe impurities in normal $\mathrm{KOH}$ solutions can be removed by treating with high-purity $\mathrm{Ni}(\mathrm{OH})_{2} . \underline{20}$ In a clean $50 \mathrm{~mL}$ polypropylene centrifuge tube, $2 \mathrm{~g}$ of $\mathrm{Ni}\left(\mathrm{NO}_{3}\right)_{2} \cdot 6 \mathrm{H}_{2} \mathrm{O}(99.99 \%)$ was dissolved in $5 \mathrm{~mL}$ of ultrapure water. $20 \mathrm{~mL}$ of $1 \mathrm{M} \mathrm{KOH}$ solution was added to give a $\mathrm{Ni}(\mathrm{OH})_{2}$ precipitate. The suspension was agitated and centrifuged, and the supernatant was decanted. The $\mathrm{Ni}(\mathrm{OH})_{2}$ precipitate was washed with ultrapure water for three times by centrifugation. The solid was dispersed in $10 \mathrm{~mL}$ of $1 \mathrm{M} \mathrm{KOH}$ by centrifugation, and the supernatant was decanted. This solid was used as the Fe-absorber. The normal $\mathrm{KOH}$ solutions could be cleaned by adding to this $\mathrm{Ni}(\mathrm{OH})_{2}$. The cleaning procedure involves dispersing $\mathrm{Ni}(\mathrm{OH})_{2}$ in the $\mathrm{KOH}$ solution, mechanically agitated over-night, followed by at least $3 \mathrm{~h}$ of resting.

\subsection{Characterizations}

Powder X-ray diffraction (PXRD) measurements were carried out on an X'Pert Philips diffractometer in Bragg-Brentano geometry with monochromatic $\mathrm{CuK} \alpha$ radiation $(0.1541 \mathrm{~nm})$ and a fast Si-PIN multistrip detector. The step size was 0.02 degree $\mathrm{s}^{-1}$. Transmission electron microscopy (TEM) was performed on an FEI Talos instrument that operated at $200 \mathrm{kV}$ high tension. Energy dispersed X-ray (EDX) mapping was used for determining the distribution of the elemental compositions. The images were collected in HAADF-STEM (High-angle annular dark-field scanning transmission electron microscopy) mode and the mapping was performed in ESpirit software. Samples for TEM were prepared by drop-drying the samples from their diluted ethanol suspensions onto carbon-coated copper grids. Suspension of FeOOH$\mathrm{NiOOH}$ was collected by sonicating the electrode in ethanol for $\mathrm{th}$ ICP-AES (Inductively coupled plasma - Atomic Emission Spectroscopy) results were obtained by a NexIon 350 (Perkin Elmer) machine. All the samples were dissolved by ultra-pure nitric acid (65\%, Merck $\mathrm{KGaA}$ ) then diluted by 30 times.

Raman spectroscopic experiments were performed at a Raman spectroscopy (inVia confocal Raman microscope, Renishaw) with a $63 x$ water immersion objective (Leica-Microsystems) for both operando and ex-situ analysis. A transparent Teflon film (o.oor in thickness, McMaster Carr) was applied to cover the lens of the objective in order to prevent direct contact with electrolyte. The wavelength of the laser excitation source was $532 \mathrm{~nm}$ with a laser power of $\sim 0.5 \mathrm{~mW}$ at a grating of $1800 \mathrm{l} \mathrm{mm}^{-1}$. Charge coupled device (CCD) detector was used to collect the scattered light from electrode surface. Prior to use, peak position of Raman spectrum was calibrated based on $520 \pm 0.5 \mathrm{~cm}^{-1}$ peak of silicon. Each spectrum was recorded with a resolution of $\sim 1$ $\mathrm{cm}^{-1}$ by setting up the measurement condition such that 30 consecutive scans and exposure time of $\mathbf{2}$ sec to laser at a beam spot were applied. All Raman experiments were carried out with a custom-made electrochemical cell in which a platinum wire and a custom-made double-junction $\mathrm{Ag} / \mathrm{AgCl}$ served as counter and reference electrodes respectively. Prior to each experiment, the cell was dipped in an acid bath to remove all traces of metals and other dirt, and subsequently it was rinsed with acetone, alcohol and distilled water. For FeOOH$\mathrm{NiOOH}$ samples, they were pressed with a hydraulic machine at 5 tons to make them flat and thin enough to fit the electrochemical Raman cell. For other powder-type samples (LDHs), the same catalyst ink as used in electrochemical measurements was drop-casted on a thin $\mathrm{Au}$ foil and then dried. The catalyst deposited Au was employed for subsequent operando Raman spectroscopy experiments.

5.3 Electrochemical test conditions
FeOOH-NiOOH (geometric area: $0.2-0.3 \mathrm{~cm}^{2}$ ) was directly used for electrochemical measurements. For NiFe LDH samples, the catalyst ink was prepared by mixing of $1 \mathrm{~mL}$ water, $0.25 \mathrm{~mL}$ isopropanol, o.o1 $\mathrm{mL} 5 \mathrm{wt} \%$ Nafion solution and $3 \mathrm{mg}$ materials. The ink was sonicated for at least $2 \mathrm{~h}$. Then $160 \mu \mathrm{L} / \mathrm{cm}^{2}$ of the ink was uniformly loaded onto a carbon cloth electrode (CC, plasma treated, geometric area: o.2-0.3 $\left.\mathrm{cm}^{2}\right)$. The electrodes were dried in a $75{ }^{\circ} \mathrm{C}$ oven for 30 mins before measurements.

All of the electrochemical measurements in this study were independently repeated for at least three times. The electrochemical measurements were performed in a three-electrode electrochemical cell, in which $\mathrm{Pt}$ wire and $\mathrm{Ag} / \mathrm{AgCl}$ electrode (saturated $\mathrm{KCl}, \mathrm{E}(\mathrm{Ag} / \mathrm{AgCl})=$ $0.197 \mathrm{~V}$ vs. NHE, normal hydrogen electrode) were used as counter and reference electrode, respectively. The working electrode and reference electrode were separated with counter electrode by a glass frit. All potentials were reported versus the reversible hydrogen electrode (RHE) unless otherwise specified. Before measurements, all of the electrolyte were calibrated the point of o V versus RHE by standard hydrogen saturation calibration experiments. A glassy carbon electrode drop-casted by $\mathrm{Pt} / \mathrm{C}$ was used as the working electrode. After bubbling with hydrogen for $30 \mathrm{mins}$, the electrode was subjected to linear scan voltammetry (LSV, scan rate: $2 \mathrm{mV} / \mathrm{s}$ ), in which the current of both hydrogen evolution and hydrogen oxidation could be observed. The cross-point is o V vs. RHE. Based on Eq. 3, the $\mathrm{pH}$ values of various electrolytes can be measured. The solution was stirred by a magnetic stirring bar in all of the electrochemical measurements. The polarization curves were recorded by LSV, and the scan rate was 1 $\mathrm{mV} / \mathrm{s}$, with $95 \%$ IR correction. The data was collected from cathodic potential to anodic potential (forward scan). 3 LSV scans were obtained for each measurements and the third LSV was used for analysis. The first LSV was typically influenced by oxidative peak. The Tafel plots were derived from LSVs. To investigate redox peaks, the scan rate was set to $10 \mathrm{mV} / \mathrm{s}$, with $90 \%$ IR correction. The activation process is performed from 1.20-1.53 V vs. RHE. The scan rate is $10 \mathrm{mV} / \mathrm{s}$, with $90 \%$ IR correction. The TOFs were calculated by Eq. 4, where J is the anodic current density at certain overpotential, A is the geometrical surface area of the electrode, $\mathrm{F}$ is the Faraday constant $(96485 \mathrm{C} / \mathrm{mol})$, and $\mathrm{m}$ is the loadings of $\mathrm{Fe}$ (assumed to be active sites).

$$
\begin{aligned}
& \mathrm{E}(\mathrm{RHE})=\mathrm{E}(\mathrm{Ag} / \mathrm{AgCl})+0.197 \mathrm{~V}+0.0592 \times \mathrm{pH} \mathrm{V} \text { (Eq. 3) } \\
& T O F=\frac{J \times A}{4 \times F \times m}
\end{aligned}
$$

Electrochemical active surface area (ECSA) was calculated from double-layer capacitance (eq 5)..$^{8}$ The $C_{s}$ the specific capacitance of monolayer $\mathrm{NiFeO}_{\mathrm{x}}\left(0.081 \mathrm{mF} / \mathrm{cm}^{2}\right)$, ${ }^{59}$ while the $\mathrm{C}_{\mathrm{dl}}$ are the double-layer capacitance of the working electrodes. The $C_{\mathrm{dl}}$ was measured according to eq 6 , where $j_{\mathrm{a}}$ and $j_{\mathrm{c}}$ are charging and discharging current densities and $v$ is the scan rate. The potential range of the measurements is from 1.00 to $1.10 \mathrm{~V}$ vs. RHE, where no catalytic current and Ni redox peaks were observed. The difference of charging and discharging current densities at $1.05 \mathrm{~V}$ was used for calculation. The scan rates were from 10 to $200 \mathrm{mV} / \mathrm{s}(10,20,50,100,150$, and $200 \mathrm{mV} / \mathrm{s})$.

$$
\begin{aligned}
& E C S A=\frac{C_{d l}}{C_{s}} \\
& C_{d l}=\frac{\left|j_{a}-j_{c}\right|}{2 v}
\end{aligned}
$$

Electrokinetic studies were performed in $\mathrm{KOH}$ with concentration from $0.5 \mathrm{M}-2 \mathrm{M}$. The $0.5 \mathrm{M}$ and $0.75 \mathrm{M} \mathrm{KOH}$ were prepared by dilute $1 \mathrm{M} \mathrm{KOH}$ standard solution, while $1.5 \mathrm{M}$ and $2 \mathrm{M} \mathrm{KOH}$ were prepared by further adding desired amount of $\mathrm{KOH}$ flakes in $1 \mathrm{M} \mathrm{KOH}$ standard solution. The LSVs of investigated electrodes were obtained sequentially in $0.5 \mathrm{M}, 0.75 \mathrm{M}, 1 \mathrm{M}, 1.5 \mathrm{M}$ and $2 \mathrm{M} \mathrm{KOH}$. The Tafel plots were derived from LSVs and linear fitted, as $(\partial \mathrm{E} / \partial \mathrm{j})_{\mathrm{pH}}$. The relationship between the potential at a constant current and the concentration of hydroxyl ions $\left(\left(\partial \mathrm{E} / \partial \log [\mathrm{OH}-]_{\mathrm{j}}\right)\right.$ were obtained by calculating the potential at a constant current $\left(10 \mathrm{~mA} / \mathrm{cm}^{2}\right.$ for FeOOH-NiOOH; $1 \mathrm{~mA} / \mathrm{cm}^{2}$ for NiFe $\mathrm{LDH})$ and $\log \left[\mathrm{OH}^{-}\right]$, and then linear fitting. The order dependence on the hydroxyl ions $\left((\partial \mathrm{j} / \partial \log [\mathrm{OH}-])_{\mathrm{E}}\right)$ in $0.5-2 \mathrm{M} \mathrm{KOH}$ can be determined according to Eq. 1. This parameter should not be di- 
rectly read from LSVs since it is hard to ensure that in a certain potential, all the current densities are in Tafel region for $\mathrm{KOH}$ with different concentrations.

Cation effect of each catalysts was investigated in $1 \mathrm{M} \mathrm{KOH}, 1 \mathrm{M} \mathrm{NaOH}$ and $1 \mathrm{M} \mathrm{LiOH}$. The point of o V vs. RHE of each electrolyte was calibrated by standard hydrogen saturation calibration method (see experimental section above). Noted that the apparent $\mathrm{pH}$ value of $\mathrm{KOH}$, $\mathrm{NaOH}, \mathrm{LiOH}$ is different, despite the same concentration. The $\mathrm{pH}$ values are 13.7, 13.5, 13.1 for $1 \mathrm{M} \mathrm{KOH}, \mathrm{NaOH}, \mathrm{LiOH}$, respectively. The LSVs of investigated electrodes were obtained sequentially in $1 \mathrm{M}$ $\mathrm{KOH}, 1 \mathrm{M} \mathrm{NaOH}$ and $1 \mathrm{M} \mathrm{LiOH}$.

$\mathrm{H} / \mathrm{D}$ isotope experiments were performed in $0.5 \mathrm{M}$ and $1 \mathrm{M}$ electrolyte. KOD in $\mathrm{D}_{2} \mathrm{O}$ solution were prepared by diluting 30\% KOD with $\mathrm{D}_{2} \mathrm{O}$ to desired concentrations. The $\mathrm{pH}$ of $\mathrm{KOH}$ was calibrated by standard hydrogen saturation calibration method. The $\mathrm{pD}$ of KOD were calculated by adding 0.87 based on $\mathrm{pH}$ of $\mathrm{KOH}$ with same concentration. This treatment is according to the different $\mathrm{pK}_{\mathrm{w}}$ values of $\mathrm{H}_{2} \mathrm{O}$ (14.0o) and $\mathrm{D}_{2} \mathrm{O}(14.87)$. The isotope effect value is calculated by the ratio of the current density in $\mathrm{KOH}$ and $\mathrm{KOD}$, in the same overpotential (Eq. 7). Noted that the theoretical potential of OER in water is $1.229 \mathrm{~V}$ vs. RHE, while that of OER in $\mathrm{D}_{2} \mathrm{O}$ is $\mathbf{1 . 2 6 2} \mathrm{V}$ vs. $\mathrm{RDE}$ (reversible deuterium electrode)..$^{50}$ Therefore, the overpotential in $\mathrm{KOH}$ and in KOD is calculated as Eq. 8-9.

$$
\begin{aligned}
& \text { Isotope effect value }=\frac{j_{K O H}}{j_{K O D}} \\
& \eta_{K O H}=E(\mathrm{Ag} / \mathrm{AgCl})+0.197 \mathrm{~V}+0.0592 \mathrm{~V} \times p H-1.229 \mathrm{~V} \\
& \eta_{K O D}=E(\mathrm{Ag} / \mathrm{AgCl})+0.197 \mathrm{~V}+0.0592 \mathrm{~V} \times(\mathrm{pq}+\mathrm{H}+0.87) \\
& -1.262 \mathrm{~V}
\end{aligned}
$$

\section{ASSOCIATED CONTENT}

Supporting Information. The supporting information contains complementary data of TEM, operando Raman spectroscopies, electrokinetic analysis and model. This material is available free of charge via the Internet at http://pubs.acs.org.

\section{AUTHOR INFORMATION}

\section{Corresponding Author}

* Xile Hu - Laboratory of Inorganic Synthesis and Catalysis, Institute of Chemical Sciences and Engineering, École Polytechnique Fédérale de Lausanne (EPFL), ISIC-LSCI, 1015 Lausanne, Switzerland; Email: xile.hu@epfl.ch.

\section{Author Contributions}

\$These authors contributed equally.

\section{Funding Sources}

This work is supported by the European Research Council (No. 681292) and and the Marie Skłodowska-Curie Fellowship (no. 838367) under the European Union's Horizon 2020 research.

Notes

The authors declare no competing financial interest.

\section{ACKNOWLEDGMENT}

We thank Dr. Natalia Gasilova (EPFL) for ICP-AES measurements.

\section{REFERENCES}

Lewis, N. S., Research opportunities to advance solar energy utilization. Science 2016, 351, aad1920.

2. Seh, Z. W.; Kibsgaard, J.; Dickens, C. F.; Chorkendorff, I.; Nørskov, J. K.; Jaramillo, T. F., Combining theory and experiment in electrocatalysis: Insights into materials design. Science 2017, 355, eaad4998.

3. Song, F.; Bai, L.; Moysiadou, A.; Lee, S.; Hu, C.; Liardet, L.; Hu, X., Transition Metal Oxides as Electrocatalysts for the Oxygen Evolution Reaction in Alkaline Solutions: An Application-Inspired Renaissance. J Am Chem Soc 2018, 140, 7748-7759.

4. Hunter, B. M.; Gray, H. B.; Muller, A. M., Earth-Abundant Heterogeneous Water Oxidation Catalysts. Chem Rev 2o16, $116,14120-14136$.

5. Suen, N. T.; Hung, S. F.; Quan, Q.; Zhang, N.; Xu, Y. J.; Chen, H. M., Electrocatalysis for the oxygen evolution reaction: recent development and future perspectives. Chem Soc Rev 2017, $46,337-365$.

6. Dau, H.; Limberg, C.; Reier, T.; Risch, M.; Roggan, S.; Strasser, P., The Mechanism of Water Oxidation: From Electrolysis via Homogeneous to Biological Catalysis. ChemCatChem 2o10, 2, 724-761.

7. Hu, C.; Zhang, L.; Gong, J., Recent progress made in the mechanism comprehension and design of electrocatalysts for alkaline water splitting. Energy Environ Sci 2019, 12, 2620-2645.

8. Man, I. C.; Su, H.-Y.; Calle-Vallejo, F.; Hansen, H. A.; Martínez, J. I.; Inoglu, N. G.; Kitchin, J.; Jaramillo, T. F.; Nørskov, J. K.; Rossmeisl, J., Universality in Oxygen Evolution Electrocatalysis on Oxide Surfaces. Chem CatChem 2011, 3, 1159-1165.

9. Koper, M. T. M., Thermodynamic theory of multi-electron transfer reactions: Implications for electrocatalysis. J Electroanal Chem 2011, 660, 254-26o.

10. Busch, M., Water oxidation: From mechanisms to limitations. Curr Opin Electrochem 2018, 9, 278-284.

11. Busch, M.; Halck, N. B.; Kramm, U. I.; Siahrostami, S.; Krtil, P.; Rossmeisl, J., Beyond the top of the volcano? - A unified approach to electrocatalytic oxygen reduction and oxygen evolution. Nano Energy 2016, 29, 126-135.

12. Bajdich, M.; Garcia-Mota, M.; Vojvodic, A.; Norskov, J. K.; Bell, A. T., Theoretical investigation of the activity of cobalt oxides for the electrochemical oxidation of water. J Am Chem Soc 2013, 135, 13521-13530.

13. Wang, L.-P.; Van Voorhis, T., Direct-Coupling O2 Bond Forming a Pathway in Cobalt Oxide Water Oxidation Catalysts. $J$ Phy Chem Lett 2011, 2, 2200-2204.

14. Bediako, D. K.; Surendranath, Y.; Nocera, D. G., Mechanistic studies of the oxygen evolution reaction mediated by a nickel-borate thin film electrocatalyst. J Am Chem Soc 2013, 135, 3662-3674.

15. Moysiadou, A.; Lee, S.; Hsu, C. S.; Chen, H. M.; Hu, X., Mechanism of Oxygen Evolution Catalyzed by Cobalt Oxyhydroxide: Cobalt Superoxide Species as a Key Intermediate and Dioxygen Release as a Rate-Determining Step. J Am Chem Soc 2020, 142, 11901-11914.

16. Surendranath, Y.; Kanan, M. W.; Nocera, D. G., Mechanistic studies of the oxygen evolution reaction by a cobalt-phosphate catalyst at neutral pH. J Am Chem Soc 2010, 132, 16501-16509. 17. Halck, N. B.; Petrykin, V.; Krtil, P.; Rossmeisl, J., Beyond the volcano limitations in electrocatalysis--oxygen evolution reaction. Phys Chem Chem Phys 2014, 16, 13682-13688.

18. Martirez, J. M. P.; Carter, E. A., Unraveling Oxygen Evolution on Iron-Doped beta-Nickel Oxyhydroxide: The Key Role of 
Highly Active Molecular-like Sites. J Am Chem Soc 2019, 141, 693705 .

19. Song, F.; Busch, M. M.; Lassalle-Kaiser, B.; Hsu, C.-S.; Petkucheva, E.; Bensimon, M.; Chen, H. M.; Corminboeuf, C.; Hu, $\mathrm{X}$., An Unconventional Iron Nickel Catalyst for the Oxygen Evolution Reaction. ACS Cent. Sci. 2019, 5, 558-568.

2o. Trotochaud, L.; Young, S. L.; Ranney, J. K.; Boettcher, S. W., Nickel-iron oxyhydroxide oxygen-evolution electrocatalysts: the role of intentional and incidental iron incorporation. J Am Chem Soc 2014, 136, 6744-6753.

21. Stevens, M. B.; Trang, C. D. M.; Enman, L. J.; Deng, J.; Boettcher, S. W., Reactive Fe-Sites in Ni/Fe (Oxy)hydroxide Are Responsible for Exceptional Oxygen Electrocatalysis Activity. $J$ Am Chem Soc 2017, 139, 11361-11364.

22. Klaus, S.; Cai, Y.; Louie, M. W.; Trotochaud, L.; Bell, A. T., Effects of Fe Electrolyte Impurities on $\mathrm{Ni}(\mathrm{OH})_{2} / \mathrm{NiOOH}$ Structure and Oxygen Evolution Activity. J Phy Chem C 2015, 119, 72437254 .

23. Friebel, D.; Louie, M. W.; Bajdich, M.; Sanwald, K. E.; Cai, Y.; Wise, A. M.; Cheng, M. J.; Sokaras, D.; Weng, T. C.; AlonsoMori, R.; Davis, R. C.; Bargar, J. R.; Norskov, J. K.; Nilsson, A.; Bell, A. T., Identification of highly active Fe sites in (Ni,Fe)OOH for electrocatalytic water splitting. J Am Chem Soc 2015, 137, 1305-1313.

24. Diaz-Morales, O.; Ledezma-Yanez, I.; Koper, M. T. M.; Calle-Vallejo, F., Guidelines for the Rational Design of Ni-Based Double Hydroxide Electrocatalysts for the Oxygen Evolution Reaction. ACS Catal 2015, 5, 5380-5387.

25. Li, Y.-F.; Selloni, A., Mechanism and Activity of Water Oxidation on Selected Surfaces of Pure and Fe-Doped NiOx. ACS Catal 2014, 4, 1148-1153.

26. Xu, X.; Song, F.; Hu, X., A nickel iron diselenide-derived efficient oxygen-evolution catalyst. Nat Commun 2016, 7, 12324.

27. Fu, D.; Keech, P. G.; Sun, X.; Wren, J. C., Iron oxyhydroxide nanoparticles formed by forced hydrolysis: dependence of phase composition on solution concentration. Phys Chem Chem Phys 2011, 13, 18523-18529.

28. Francas, L.; Corby, S.; Selim, S.; Lee, D.; Mesa, C. A.; Godin, R.; Pastor, E.; Stephens, I. E. L.; Choi, K. S.; Durrant, J. R., Spectroelectrochemical study of water oxidation on nickel and iron oxyhydroxide electrocatalysts. Nat Commun 2019, 10, 5208.

29. Stern, L. A.; Hu, X., Enhanced oxygen evolution activity by $\mathrm{NiOx}$ and $\mathrm{Ni}(\mathrm{OH})_{2}$ nanoparticles. Faraday discussions 2014, $176,363-379$.

3o. Chen, J.; Zheng, F.; Zhang, S.-J.; Fisher, A.; Zhou, Y.; Wang, Z.; Li, Y.; Xu, B.-B.; Li, J.-T.; Sun, S.-G., Interfacial Interaction between FeOOH and Ni-Fe LDH to Modulate the Local Electronic Structure for Enhanced OER Electrocatalysis. ACS Catal 2018, 8, 11342-11351.

31. Yin, H.; Jiang, L.; Liu, P.; Al-Mamun, M.; Wang, Y.; Zhong, Y. L.; Yang, H.; Wang, D.; Tang, Z.; Zhao, H., Remarkably enhanced water splitting activity of nickel foam due to simple immersion in a ferric nitrate solution. Nano Research 2018, 11, 39593971.

32. Lee, S.; Bai, L.; Hu, X., Deciphering Iron-Dependent Activity in Oxygen Evolution Catalyzed by Nickel-Iron Layered Double Hydroxide. Angew Chem Int Ed 2020, 59, 8072-8077.

33. Lee, S.; Banjac, K.; Lingenfelder, M.; Hu, X., Oxygen Isotope Labeling Experiments Reveal Different Reaction Sites for the Oxygen Evolution Reaction on Nickel and Nickel Iron Oxides. Angew Chem Int Ed 2019, 58, 10295-10299.
34. Trzesniewski, B. J.; Diaz-Morales, O.; Vermaas, D. A.; Longo, A.; Bras, W.; Koper, M. T.; Smith, W. A., In Situ Observation of Active Oxygen Species in Fe-Containing Ni-Based Oxygen Evolution Catalysts: The Effect of $\mathrm{pH}$ on Electrochemical Activity. J Am Chem Soc 2015, 137, 15112-15121.

35. Louie, M. W.; Bell, A. T., An investigation of thin-film $\mathrm{Ni}$-Fe oxide catalysts for the electrochemical evolution of oxygen. J Am Chem Soc 2013, 135, 12329-12337.

36. Diaz-Morales, O.; Ferrus-Suspedra, D.; Koper, M. T. M., The importance of nickel oxyhydroxide deprotonation on its activity towards electrochemical water oxidation. Chem Sci 2016, 7 , 2639-2645.

37. Lu, Z.; Xu, W.; Zhu, W.; Yang, Q.; Lei, X.; Liu, J.; Li, Y.; Sun, X.; Duan, X., Three-dimensional NiFe layered double hydroxide film for high-efficiency oxygen evolution reaction. Chem Commun 2014, 50, 6479-6482.

38. Zou, S.; Burke, M. S.; Kast, M. G.; Fan, J.; Danilovic, N.; Boettcher, S. W., Fe (Oxy)hydroxide Oxygen Evolution Reaction Electrocatalysis: Intrinsic Activity and the Roles of Electrical Conductivity, Substrate, and Dissolution. Chem Mater 2015, 27, 80118020 .

39. Bockris, J. O. M., Kinetics of activation controlled consecutive electrochemical reactions: anodic evolution of oxygen. $J$ Chem Phy 1956, 24, 817-827.

4o. Lyons, M. E. G.; Brandon, M. P., A comparative study of the oxygen evolution reaction on oxidised nickel, cobalt and iron electrodes in base. J Electroanal Chem 2010, 641, 119-130.

41. Fang, Y.-H.; Liu, Z.-P., Tafel Kinetics of Electrocatalytic Reactions: From Experiment to First-Principles. ACS Catal 2014, 4, 4364-4376.

42. Vrubel, H.; Moehl, T.; Gratzel, M.; Hu, X., Revealing and accelerating slow electron transport in amorphous molybdenum sulphide particles for hydrogen evolution reaction. Chem Commun 2013, 49, 8985-8987.

43. Chung, D. Y.; Park, S.; Lopes, P. P.; Stamenkovic, V. R.; Sung, Y.-E.; Markovic, N. M.; Strmcnik, D., Electrokinetic Analysis of Poorly Conductive Electrocatalytic Materials. ACS Catal 2o2o, 10, 4990-4996.

44. Garcia, A. C.; Touzalin, T.; Nieuwland, C.; Perini, N.; Koper, M. T. M., Enhancement of Oxygen Evolution Activity of Nickel Oxyhydroxide by Electrolyte Alkali Cations. Angew Chem Int Ed 2019, 58, 12999-13003.

45. $\quad$ Michael, J. D.; Demeter, E. L.; Illes, S. M.; Fan, Q.; Boes, J. R.; Kitchin, J. R., Alkaline Electrolyte and Fe Impurity Effects on the Performance and Active-Phase Structure of $\mathrm{NiOOH}$ Thin Films for OER Catalysis Applications. J Phy Chem C 2015, 119, 11475-11481.

46. Zaffran, J.; Stevens, M. B.; Trang, C. D. M.; Nagli, M.; Shehadeh, M.; Boettcher, S. W.; Caspary Toroker, M., Influence of Electrolyte Cations on $\mathrm{Ni}(\mathrm{Fe}) \mathrm{OOH}$ Catalyzed Oxygen Evolution Reaction. Chem Mater 2017, 29, 4761-4767.

47. Parkin, G., Temperature-Dependent Transitions Between Normal and Inverse Isotope Effects Pertaining to the Interaction of $\mathrm{H}-\mathrm{H}$ and $\mathrm{C}-\mathrm{H}$ Bonds with Transition Metal Centers. Acc Chem Res 2009, 42, 315-325.

48. Zhang, W.; Burgess, I. J., Kinetic isotope effects in proton coupled electron transfer. J Electroanal Chem 2012, 668, 6672.

49. Pasquini, C.; Zaharieva, I.; Gonzalez-Flores, D.; Chernev, P.; Mohammadi, M. R.; Guidoni, L.; Smith, R. D. L.; Dau, H., H/D Isotope Effects Reveal Factors Controlling Catalytic Activity 
in Co-Based Oxides for Water Oxidation. J Am Chem Soc 2019, 141, 2938-2948.

50. Sakaushi, K., Quantum electrocatalysts: theoretical picture, electrochemical kinetic isotope effect analysis, and conjecture to understand microscopic mechanisms. Phys Chem Chem Phys 2020, 22, 11219-11243.

51. Krishtalik, L. I., The mechanism of the proton transfer: an outline. Biochimica et Biophysica Acta (BBA) - Bioenergetics 2000, 1458, 6-27.

52. Gómez-Gallego, M.; Sierra, M. A., Kinetic Isotope Effects in the Study of Organometallic Reaction Mechanisms. Chem Rev 2011, 111, 4857-4963.

53. Zhang, Y.; Zhang, H.; Ji, H.; Ma, W.; Chen, C.; Zhao, J., Pivotal Role and Regulation of Proton Transfer in Water Oxidation on Hematite Photoanodes. J Am Chem Soc 2016, 138, 27052711.

54. Liu, Y.; McCrory, C. C. L., Modulating the mechanism of electrocatalytic $\mathrm{CO}_{2}$ reduction by cobalt phthalocyanine through polymer coordination and encapsulation. Nat Commun 2019, 10, 1683 .
55. Li, W.; Li, F.; Yang, H.; Wu, X.; Zhang, P.; Shan, Y.; Sun, L., A bio-inspired coordination polymer as outstanding water oxidation catalyst via second coordination sphere engineering. Nat Commun 2019, 10, 5074 .

56. Li, N.; Bediako, D. K.; Hadt, R. G.; Hayes, D.; Kempa, T. J.; von Cube, F.; Bell, D. C.; Chen, L. X.; Nocera, D. G., Influence of iron doping on tetravalent nickel content in catalytic oxygen evolving films. Proc Natl Acad Sci USA 2017, 114, 1486.

57. Xu, L.; Wang, Z.; Chen, X.; Qu, Z.; Li, F.; Yang, W., Ultrathin layered double hydroxide nanosheets with $\mathrm{Ni}$ (III) active species obtained by exfoliation for highly efficient ethanol electrooxidation. Electrochim Acta 2018, 26o, 898-904.

58. McCrory, C. C.; Jung, S.; Peters, J. C.; Jaramillo, T. F., Benchmarking heterogeneous electrocatalysts for the oxygen evolution reaction. J Am Chem Soc 2013, 135, 16977-16987.

59. Batchellor, A. S.; Boettcher, S. W., Pulse-Electrodeposited $\mathrm{Ni}-\mathrm{Fe}$ (Oxy)hydroxide Oxygen Evolution Electrocatalysts with High Geometric and Intrinsic Activities at Large Mass Loadings. ACS Catal 2015, 5, 6680-6689. 
Table of contents (TOC)

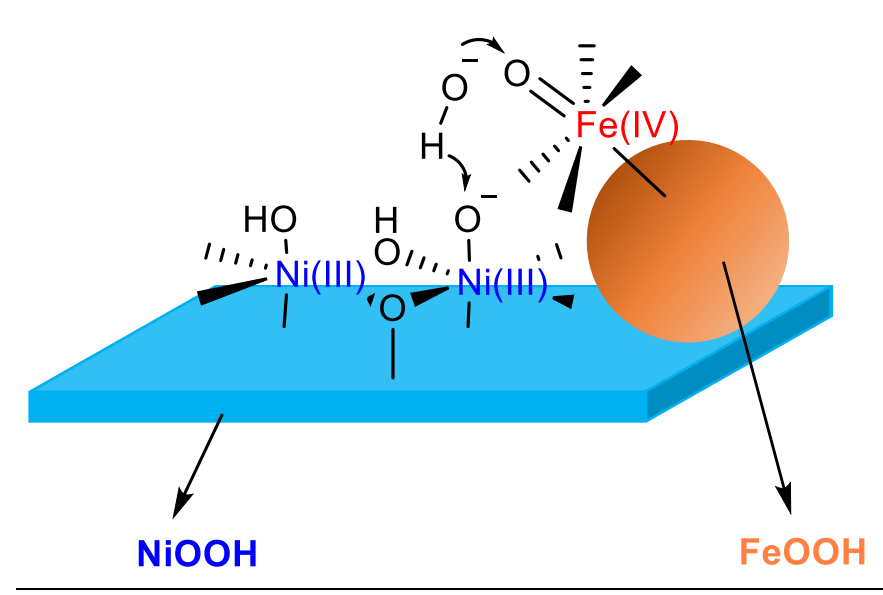

13 